\title{
AIRBORNE DATA LINK STUDY REPORT
}

\author{
Albert J. Rehmann \\ January 1996 \\ DOT/FAA/CT-TN95/62
}

JANUARY 1996 
Technical Report Documentation Page

\begin{tabular}{|c|c|c|}
\hline $\begin{array}{l}\text { 1. Report No. } \\
\text { DOT/FAA/CT-95/62 }\end{array}$ & 2. Government Accession No. & 3. Recipient's Catalog No. \\
\hline \multirow{2}{*}{\multicolumn{2}{|c|}{$\begin{array}{l}\text { 4. Title and Subtitle } \\
\text { AIRBORNE DATA LINK STUDY REPORT }\end{array}$}} & $\begin{array}{l}\text { 5. Report Date } \\
\text { January } 1996\end{array}$ \\
\hline & & $\begin{array}{l}\text { 6. Performing Organization Code } \\
\text { ACT-350 }\end{array}$ \\
\hline \multicolumn{2}{|c|}{$\begin{array}{l}\text { 7. Author(s) } \\
\text { Albert J. Rehmann; Richard H. Mogford, CTA }\end{array}$} & $\begin{array}{l}\text { 8. Performing Organization Report No. } \\
\text { DOT/FAA/CT-95/62 }\end{array}$ \\
\hline \multirow{3}{*}{\multicolumn{2}{|c|}{$\begin{array}{l}\text { 9. Performing Organization Name and Address } \\
\text { CTA INCORPORATED } \\
\text { 2500 English Creek Avenue, Suite } 1000 \\
\text { Pleasantville, NJ } 08232\end{array}$}} & 10. Work Unit No. (TRAIS) \\
\hline & & $\begin{array}{l}\text { 11. Contract or Grant No. } \\
\text { DTFA03-89-C-00023 }\end{array}$ \\
\hline & & 13. Type of Report and Period Covered \\
\hline \multirow{2}{*}{\multicolumn{2}{|c|}{$\begin{array}{l}\text { 12. Sponsoring Agency Name and Address } \\
\text { U.S. Department of Transportation } \\
\text { Federal Aviation Administration Technical Center } \\
\text { Atlantic City International Airport, NJ } 08405\end{array}$}} & Technical Report \\
\hline & & 14. Sponsoring Agency Code \\
\hline
\end{tabular}

15. Supplementary Notes

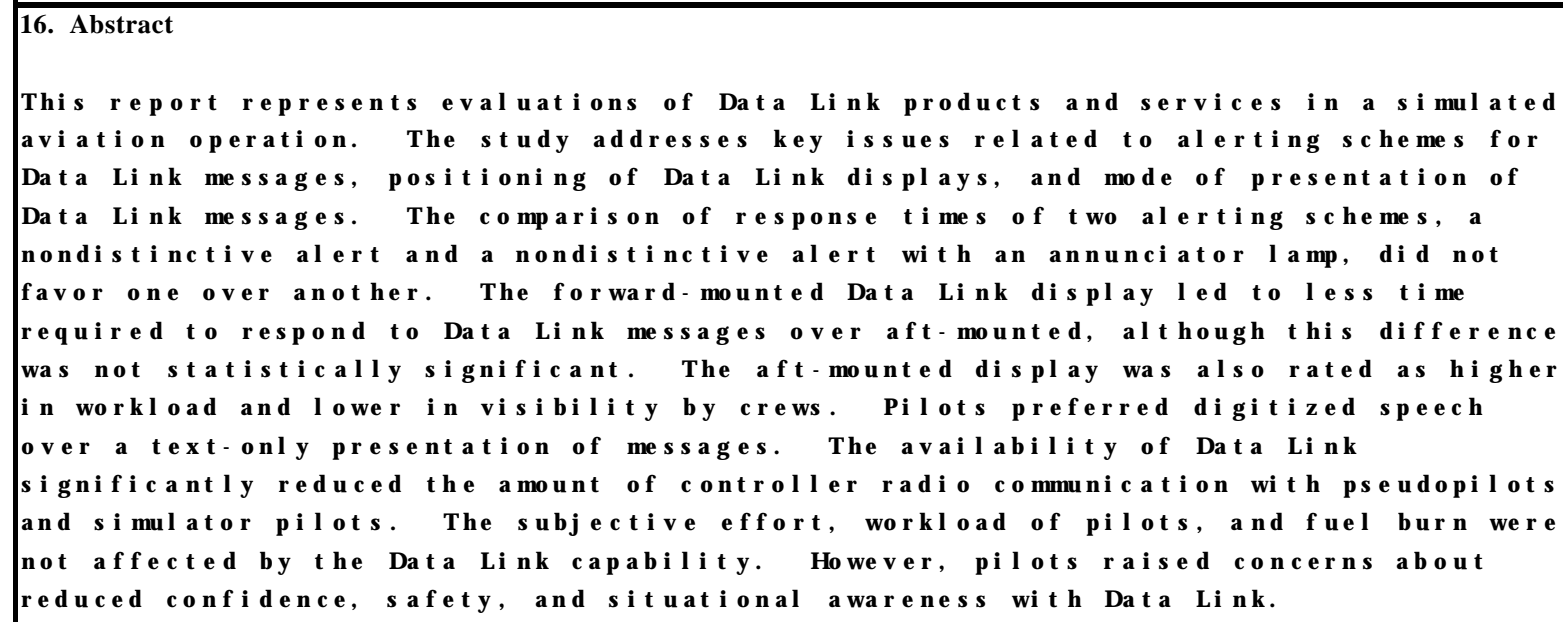

\section{Key Words}

Data Link Situational Awareness

Crew Alerting Display Location
18. Distribution Statement

This document is available to the public through the National Technical Information Service, Springfield, VA 22161

\begin{tabular}{|l|l|l|l|}
\hline 19. Security Classif.(of this report) & 20. Security Classif.(of this page) & 21. No. of Pages \\
Unclassified & Unclassified & 67 \\
\hline
\end{tabular}


1.1 Overview

1.2 Purpose

1.3 Scope

1.4 Research Questions

2. EXPERIMENTAL APPARATUS 3

2.1 ATC Simulator

2.2 Aircraft Simulator Sites

2.3 Displays

2.4 Crew Alerting

2.5 Speech Production

3

3

4

4

5

3. SUBJECTS 6

4. EXPERIMENTAL DESIGN 6

4.1 Experimental Factors Description 6

4.2 Test Design 8

4.3 Number of Runs 9

4.4 Dependent Measures 9

4.5 ATC Messages 13

4.6 Flight Scenarios 13

4.7 Support Personnel 14

4.8 Data Reduction and Analysis 15

5. RESULTS 15

$\begin{array}{ll}5.1 & \text { Communication Activity } \\ 5.2 & 15\end{array}$

5.2 Situation Awareness 19

5.3 Subjective Effort 24

5.4 Data Link Attention Requirements 26

5.5 Fuel Burn 29

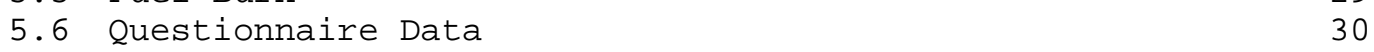

6. DISCUSSION 33

6.1 Crew Alerting 33

6.2 Display Location $\quad 35$

6.3 Method of Communication 37

6.4 Other Issues 40

7. CONCLUSIONS 41

$\begin{array}{lll}7.1 & \text { Crew Alerting } & 41\end{array}$

TABLE OF CONTENTS (Continued)

Page 
7.2 Display Location 42

7.3 Communication Type 43

7.4 Data Link Response Time 44

7.5 Navigational Input Before WILCO 44

7.6 CDU Ergonomics 45

7.7 Summary 45

8. REFERENCES 46

APPENDIX

A - Video Analysis Procedure

LIST OF ILLUSTRATIONS

$\begin{array}{ll}\text { Figures } & \text { Page }\end{array}$

1 Experimental Design 6

2 Key Cockpit and ATC Uplink and Downlink Events 10

3 Graph of WILCO Response Times 18 
4 Crew Responses to Bad Weather Report 21

5 Map Situation Awareness Data 22

6 Probe Question Situation Awareness Data 23

7 Interaction Plot for Pilot Opinion 32 
LIST OF TABLES

Table

Page

1 Situation Awareness Items

11

2 Controller Communication Activities 16

3 Path Change Epoch Times for Type of Crew Alert 19

4 Path Change Epoch Times for CDU Location 19

5 Path Change Epoch Times for Communication Type 19

6 Percent of Flights Crew Discussed 20

7 Number of Aircraft and Items Recalled per Flight 21

8 Pilot Answers to Probe Questions 22

9 Situation Awareness Questionnaire Items (0 to 5 Scale) 23

10 Subjective Effort for PNF for Crew Alert Factor 24

11 Subjective Effort for PF for Crew Alert Factor 25

12 Subjective Effort for PNF for Display Location Factor 25

13 Subjective Effort for PF for Display Location Factor 25

14 Subjective Effort for PNF as a Function of 26

Communication Type

15 Subjective Effort for PF as a Function of 26 Communication Type

16 Percent of Total Data Link Messages 27

17 Percent of Total Data Link Messages 27

18 Percent of Total Data Link Messages 28

19 Percent of Total Data Link Messages 28

20 PF Activities for All Simulators (in Percent) 29

21 Fuel Burn for Each Simulator (in Pounds) 30

22 Crew Alert CDU Ergonomics (0 to 5 Scale) 30

23 CDU Location Ergonomics (0 to 5 Scale) 31

24 Average Pilot Ratings of Communication Options 31

EXECUTIVE SUMMARY

This is the first in a series of evaluations of Data Link products and services where pilots and controllers participate in simulations of aviation operations. Establishment of guidelines for cockpit implementation of Data Link computer-human interfaces (CHI) was the focus. To this end, the 
experiment addressed a number of cockpit Data Link human factors issues that were identified as important by the Airline Transport Association (ATA) and other bodies.

Using a network of four flight simulators, this evaluation examined crew alerting methods, display location, and presentation of Data Link messages. Findings are generalizable to the airspace, air traffic control (ATC) systems, and aircraft types used in the study.

The first research question was: What kind of alerting scheme is required to distinguish alerts for Data Link messages from other cockpit alerts?

Specifically, it was decided to study whether there is a difference in pilot communication behavior (response time to a Data Link message) between the conditions of nondistinctive (selective calling (SELCAL) sound only) versus unique (SELCAL sound plus ATC-labeled light) alerts.

The second research question posed was: What is the acceptability of an aftcenter pedestal mounted control display unit (CDU) given the head-up requirements of terminal operations? This issue was of interest because of the need to consider aft-CDU locations in order to retrofit some cockpits with Data Link.

The third research question addressed presentation of Data Link messages. There was interest in whether digitized speech announcement of incoming Data Link messages would improve pilot response time and result in reduced head down time. The study compared three message presentation formats: radio, Data Link text format, and Data Link text format plus digitized speech.

\section{EQUIPMENT.}

Two B-727-200 simulators; one B-727-100, and one B-737-300 simulator were networked into the Automated Radar Terminal System (ARTS) IIIA laboratory at the Federal Aviation Administration (FAA) Technical Center. Three of the four were equipped with Data Link annunciation lamps mounted under the glare shield, one prominent in the field of view of the left seat, and one prominent in the field of view of the right.

Each simulator had a Honeywell CD-800 Data Link CDU mounted in the center pedestal. Three had CDUs mounted forward of the throttles and one had the CDU placed behind the throttles. Auditory alerting and speech production were provided by personal computer (PC)-generated sounds played over a loudspeaker. 
SUBJECTS.

Subject pilots were type-rated in the aircraft that they operated. First officers were qualified (but not necessarily type-rated) in the specific aircraft.

EXPERIMENTAL DESIGN.

There were three equipment-related independent variables. These were crew alerting, display location, and message display. The experiment was divided into two parts, each considering two of the experimental factors. Message display was common for all sites but alerting and display location were tested in separate pairs of simulators.

Test Design.

The message display factor had three levels, and the alerting and display location factors each had two resulting in two, 3x2, mixed plot, factorial experimental designs. The CDU location and alerting variables were betweensubjects factors while the message display factor was within-subjects.

Experimental trials were conducted for 8 days for 8 hours per day. Prior to the first experimental run, a 20-minute Data Link practice flight was completed without the simulators being on-line with the FAA Technical Center systems. Following this were three data collection runs (one for each communication type). Each lasted 1-1/2 hours, thus allowing for three runs per day. The order of the runs was counterbalanced to compensate for practice effects.

Five days of successful data collection were completed resulting in 15 runs per simulator site. Pilots flew a minimum of three flights per run and alternated roles of pilot flying (PF) and pilot not flying (PNF) between each flight. This created a total of at least 45 flights per site over the 5 days.

The dependent variables in this evaluation were:

1. Communication activity (effort, errors, and time intervals). 2 . Situation awareness (SA).

3. Workload.

4. Data Link attention requirements.

5. Fuel Burn.

6. Crew interactions.

7. Subjective opinions regarding the cockpit Data Link interface, alerting methods, display location, and speech synthesis. 
Flight Scenarios.

One basic flight scenario was written for the experiment and each aircrew experienced it three times (twice in the Data Link conditions and once in the speech condition). Runs lasted 1-1/2 hours each with three or four arrival flights per run. Aircraft were 100 percent radio (no Data Link) in the radioonly communication condition and a mixture of 80 percent Data Link and 20 percent radio-only equipped in the Data Link communication conditions. Flight simulators were always Data Link equipped in Data Link runs but were permitted to use radio communication.

Flights were conducted in the Raleigh-Durham terminal airspace. Conditions were visual flight rules with a 1,000-foot ceiling and 3 miles visibility. Flight simulators and computer-generated aircraft flew downwind or near straight-in approaches to both runways. No departures were flown. Flight simulators were assigned to one type of approach and alternated runways.

RESULTS AND DISCUSSION.

Each research issue is discussed in the following sections. In the interest of space, most numerical results and all statistical tests are excluded (details are available in the main body of the report).

Crew Alerting.

There was no statistically significant difference in alert epoch ${ }^{1}$ response time between simulators with nondistinctive versus unique alerts.

There was a significant difference in the will comply (WILCO) epoch ${ }^{2}$ between the two simulators, with the nondistinctive alert being faster. It was discovered that the inflight observer had suggested to the nondistinctivealert flight simulator crews that they WILCO Data Link messages before making navigational changes to the aircraft. It is suspected that the effort to WILCO immediately by at least some of the crews for some of the time at the nondistinctive alert site shortened the WILCO epoch times. There were no significant differences in path change epoch times ${ }^{3}$ as a function of alerting scheme.

There were no subjective effort differences for the PF or PNF (workload, time busy, amount of thinking, and general stress) as a result of different types of crew alerting. There were also no significant differences in the number of times the PF glanced at alerting type. The number of times the PNF read from the CDU was also not affected.

1 The time between message alert and message access.

2 The time between message access and WILCO.

${ }^{3}$ The time between WILCO and aircraft heading or altitude change. 
Pilots were also asked to give their opinions regarding the two kinds of crew alerting. No significant differences in the rating scales were found between the two simulator sites. There were some comments that the alerting sound used should be unique and not a general purpose cockpit alert. Some pilots thought the glare shield lights were inappropriate and one pilot liked the idea of an indicator on the CDU. It should be noted that crews did not have the opportunity directly to compare the alerting systems.

Display Location.

There was a statistically significant alert response time difference between the cockpits with aft-mounted and forward-mounted displays. Although there was a 1.4 seconds difference between the simulators in average time from access to WILCO, this was not statistically significant. Display location did not significantly affect path change epoch times.

PNFs (who were responsible for Data Link operation) rated the subjective effort associated with the aft-mounted display as significantly higher in workload, and the other effort factors approached statistical significance, favoring the forward-mounted display. PF subjects did not indicate any difference in any effort measure between the two display locations.

Videotape analysis yielded a number of kinds of information about display placement. First, it was found that the PF did not glance at the Data Link CDU as often when it was mounted in the aft location (about 82 percent of messages for forward-mounted and 34 percent for aft-mounted). This result was statistically significant and was averaged across Data Link communication modes (text-only and text with speech).

The length of the average glance, number of times the PF read the message out loud (about 33 percent of all incoming messages), and time at which the message was read, were not affected by display location. This indicates that those PFs who used the aft-mounted display almost always read the Data Link message out loud if they glanced at the CDU.

With regard to the $\mathrm{PNF}$, there were no differences for CDU location in the number of times this crew member read a Data Link message out loud or when the message was read. Thus, it can be assumed that the PNF's duty of reading out each Data Link message was carried out in a similar way for each CDU configuration.

The questionnaire data with respect to CDU ergonomics covered the following factors: alert, vision, reach, readability, and usability. The only significant difference for the display location factor was in vision; the aftmounted display was rated as less visible than the forward-mounted CDU. Written comments indicated a small number of notes regarding problems with forward- and aft-CDU placement. There was an absence of real criticism of the aft-mounted display but flight crews did not have a chance to make a direct comparison between CDU location types. 
Method of Communication.

While no statistically significant differences were found between Data Link communication types for the alert response time in any simulator, time required to WILCO was longer for digitized speech. Videotape review of crew activities indicated that pilots were able to read messages from the CDU faster than the time required for the digitized speech to play. However, the CDU software did not allow the PNF to WILCO until the speech had finished playing. If the messages had been recorded at a higher cadence, this time difference might have disappeared. It is likely that reading text from the screen will always be faster than hearing it read out loud. There were no significant differences in path change epoch times as an effect of communication type.

Four types of SA data were collected during the study. With regard to flight crew responses to problem weather reports, there appeared to be slightly more crew discussion about the weather situation in Data Link runs as compared to radio-only.

The map and probe question SA data demonstrated more graphic differences between Data Link and radio-only. Recall of aircraft data was less than one item per flight (on average) during Data Link runs. However, when radio was used exclusively, pilots recalled an average of three items per flight. The probe question data were similar in that the raw answer rate for radio-only was nearly twice as great as for Data Link.

Questionnaire data gathered immediately after each run showed no significant differences across communication conditions for ease of use or planning capability, but indicated that Data Link was seen by pilots as promoting less confidence and perception of safety. Ratings on an end-of-day SA questionnaire revealed that pilots thought Data Link would result in a reduction in knowledge of weather and separation from other aircraft and would reduce aircrew ability to anticipate ATC instructions, clearances, next sector, and landing sequence. In their written comments, most pilots were concerned that Data Link would reduce their ability to detect ATC errors.

There were no significant differences in PNF or PF subjective effort ratings between radio and the two Data Link display conditions for all sites. This indicates that the method of communicating ATC messages did not affect crew workload in any measurable way.

Crew communication activities were influenced by communication mode. With the provision of digitized speech, the PF glanced at the CDU significantly less often and glance duration was shorter. The PNF's duty to glance at the CDU to read incoming Data Link transmission did not change with the provision of digitized speech. However, when digitized speech was provided, the PNF read Data Link messages out loud less frequently. It was also found that the PF and PNF did not verbalize the Data Link message verbatim as often when speech was provided. Thus there were shifts in crew activities in the direction of less work confirming Data Link messages.

When asked about their preferences for digitized speech over a text-only presentation, there was a significant difference of opinion in favor of the speech mode. The ratings for Data Link with speech averaged 4.1 (on a 0 to 5 scale) and 3.5 for text-only. However, further analysis indicated that the difference between speech and text-only Data Link was primarily found at one simulator site. Crews who flew the simulator with the aft-mounted display had the poorest opinion of the text mode, rating it at 2.8 as opposed to 4.0 for speech (on a 0 to 5 scale). Display placement in a less visible position probably made the provision of speech more desirable. 
Pilot written comments were in favor of the digitized speech presentation of Data Link messages, although some improvements were recommended. The speed of the speech should be increased and it should not interfere with radio traffic.

Total Data Link Response Time.

The shortest average total turnaround time to Data Link messages in the cockpit was 11.1 seconds. This result is similar to that found in other Data Link studies.

Navigational Input Before WILCO.

Videotape analysis of flight crew activity immediately following the receipt of a Data Link communication revealed that for 87.5 percent of all messages, one of the pilots began making navigational changes to the aircraft (manually or through inputs to the autopilot) before WILCOing.

CDU Ergonomics.

Data Link CDUs in all cockpits received ratings of three or above with many ratings over four (on a 0 to 5 scale) on alert, vision, reach, readability, and usability. The only exception was for the aft-mounted display which was rated 2.7 for vision. Data Link was valued for its ability to provide text of ATC instructions so that pilots could check frequency changes, clearances, etc. These results indicate that the Data Link CDU was accepted well by flight crews.

A number of suggestions for improvement were made in written comments. Pilots mentioned the ease of use of the Data Link interface and suggested making the WILCO button flash, having a Data Link access key on the yoke, allowing the radio to override Data Link speech, and improving system status displays.

Difficulty with making transfer of communication (TC) responses was mentioned.

CONCLUSIONS.

Crew Alerting.

The setting for this study was not conducive for a definitive test of Data Link alerting possibilities. Nevertheless, a nondistinctive alerting sound was evaluated against the same sound plus a unique annunciator lamp. There was no response time, subjective effort, crew activity, or preference rating differences supporting either option. The primary suggestion from flight crews appeared to be to change the SELCAL sound to a unique sound distinguishable from other cockpit aural indicators.

The data did not support that a unique alert would be more effective than a nondistinctive alert and also did not show it to be preferred by flight crews. This study has not established that the provision of a unique Data Link alerting system in the terminal environment is needed. It appears that, if simplicity in an alerting system is desired, a SELCAL sound alone may support acceptable crew performance. However, a further experiment, focused exclusively on Data Link crew alerting, is needed to address the unanswered questions.

Display Location.

Although it required 0.4 seconds longer for the PNF to respond to a Data Link alert with the aft-mounted display, this does not represent a meaningful time difference. This location was also associated with higher workload and lower 
visibility. Crew coordination may have been degraded in that the PF did not look at the aft-mounted display as often. However, flight crews did not indicate a distinct preference (in their comments) for either location. There was a relative dislike for text-only presentation in the aft location, as compared to digitized speech. It appears that the use of speech with an aftmounted display may offset some of its disadvantages.

Based on these data, an aft-mounted Data Link CDU may be acceptable, if necessary, with certain qualifications. Crew cross-checking of Data Link information could be supported by procedures such as PNF announcement of screen contents. The provision of digitized speech would obviate the need for the $\mathrm{PF}$ to glance at the $\mathrm{CDU}$ and would ensure a reliable check on Data Link messages for both crew members. However, further study is needed of the possibly disruptive effect of Data Link CDU operation (especially with an aftmounted $\mathrm{CDU}$ ) on PNF tasks.

Communication Type.

The finding that response epoch times were longer for Data Link with speech was no doubt a function of the slow cadence of the controller's recorded voice. While this delay could be reduced by speeding up the speech rate, it is likely that pilots will usually be able to read faster than the message can be spoken. To avoid delaying a WILCO response, it might be wise to allow the WILCO input before the speech system has finished. This would permit the crew to read the message from the screen, WILCO, and still hear the audible message for confirmation.

Data Link was generally well received by flight crews. Crew subjective effort was not affected by the presence of Data Link capabilities. Pilot concerns mainly focused on the SA issues. While the problem weather SA data suggested some increased discussion under Data Link conditions, there were clear indications of a loss of awareness for navigational information regarding surrounding aircraft in the map and probe question results. Questionnaire ratings also showed that pilots perceived Data Link to be associated with reduced confidence and safety and were concerned about the effects of the loss of the radio party line on their SA.

The effects of SA reduction on pilot performance are not yet established but pilots in this study voiced their concerns about confidence, safety, and SA reduction. Methods may have to be developed to offset the reduction in traffic SA when Data Link is in almost exclusive use as a communication medium.

With regard to the use of speech digitization of Data Link messages, it was found that $\mathrm{PF}$ and PNF coordination activities that involved glancing at and reading Data Link messages were reduced when speech was provided. Pilots preferred speech when an aft-mounted display was in use.

Data Link Response Time.

Best average cockpit turnaround time for Data Link messages was 11.1 seconds. Future Data Link studies can use this value as a realistic estimate of flight crew response times to Data Link messages in a terminal environment with similar cockpit equipage. It may be possible to reduce this time through implementation of specific cockpit procedures, such as to WILCO before making navigational changes.

Navigational Input Before WILCO.

For most Data Link messages, flight crews made navigational inputs to their simulators before they WILCOed. This was true irrespective of Data Link 
condition. This result may have implications for ATC-flight crew coordination. However, path change response time data indicate that by the time the aircraft's altitude or heading begins to change, the WILCO may have already been received by ATC. Nevertheless, cockpit procedures may need to be considered to ensure a timely WILCO from the flight crew.

\section{CDU Ergonomics.}

Data Link CDUs and software were rated as acceptable in most cases. However, there were problems with the TC response sequence and flight crews made a number of suggestions. The TC sequence used in this study should be modified to improve throughput and error rate (noncompletion). Pilot suggestions included adding a flashing WILCO reminder, positioning the message access key on the yoke, allowing radio to override Data Link speech, and improving system status displays.

$\underline{\text { Summary }}$.

This study achieved a number of important goals. First, it has been established that the FAA Technical Center test bed developed for the experiment is capable of supporting an extensive cockpit Data Link study involving multiple simulators. A number of important data extraction tools have also been developed, including on-site PCs for Data Link messages and crew response times, cockpit video systems, and software to extract time and communication data from various computer records.

While further study is required on crew alerting, information has been gathered that outlines the direction for this work. It has been tentatively established that aft-mounted Data Link CDUs are feasible, with certain qualifications. Pilot response time to Data Link messages in the terminal environment has been established (for the aircraft and conditions of this study) and is supported by a large number of data points. Finally, good progress has been made in establishing the viability of the chosen CHI design for cockpit Data Link and the feasibility and desirability of digitized speech for announcement of Data Link messages.

\section{INTRODUCTION.}

\subsection{OVERVIEW.}

This is the first in a series of evaluations of Data Link products and services where pilots and controllers participate in simulations of aviation operations.

\subsection{PURPOSE.}

This evaluation examined crew alerting methods, display location, and presentation of Data Link messages. Recommendations are made regarding the acceptability of implementation options relative to operations in terminal airspace. Findings are generalizable to the air traffic control (ATC) systems and aircraft types used in the study.

Establishment of guidelines for cockpit implementation of Data Link computer-human interfaces (CHI) was the focus of this evaluation. To this end, the experiment addressed a number of cockpit Data Link human factors issues that have been identified as important by the Airline Transport A ssociation (ATA) and other bodies.

\section{$1.3 \quad \mathrm{SCOPE}$.}

The cockpit Data Link CHI study assessed a selected set of terminal Data Link services. Air traffic controllers interacted with radar displays driven by Automated Radar Terminal System (ARTS) IIIA equipment. A thorough 
description of the ARTS IIIA implementation is contained in [1] Pilots interacted with control display units (CDUs) in cockpit simulators.

Flight deck data collection was limited to four analog display aircraft including one B-737 and three B-727 flight simulators. The rationale for using analog instrument cockpits was the flexibility offered in installing and interfacing display devices and crew alerting schemes. Moreover, the analog phase II cockpit simulators available for research purposes could incorporate Data Link without risking decertification. A utomated entry of data clearances into flight controls was not part of the test design. Federal A viation Administration (FAA) researchers felt that for this particular evaluation, the simpler CDU configuration was better understood and more easily controlled than a flight management computer (FMC) configuration with coupled flight control.

\subsection{RESEARCH QUESTIONS.}

The ATA Information Transfer Subcommittee paper [2] Research questions addressed in this report were derived in part from [2].

The first research question was: What kind of alerting scheme is required to distinguish alerts for Data Link messages from other cockpit alerts? was, in part, motivated by section 5.5.3 of [2], "Distinction of Alerts." The FAA's Aircraft Certification O ffice has been preparing requirements for domestic cockpit Data Link systems and is considering the need for light and sound annunciation of Data Link messages. FAA flight test pilots expect that some combination of an indicator light and alerting sound may be needed to provide a unique Data Link annunciation. This could be a nondistinctive sound with a distinctive light (or message common to other such alerts) or a nondistinctive light or message with a distinctive sound.

It was decided to test the former situation because many analog instrument cockpits already have a nondistinctive message sound known as the selective calling (SELCAL) signal. A major airframe manufacturer is also apparently considering the use of a general purpose communication annunciating sound in future cockpits. The addition of a distinctive light provided a unique D ata Link alerting scheme. Therefore, the research question of interest was whether there is a difference in pilot communication behavior (response time to a Data Link message) between the conditions of nondistinctive (SELCAL sound only) versus distinctive (SELCAL sound plus ATC-labeled light) alerts.

Given the low frequency of SELCAL alerts for company or cabin calls in terminal airspace, a SELCAL sound was associated with a Data Link message most of the time. Therefore, it was anticipated that there would not be much difference in pilot response time between the two alerting conditions unless the light (which stayed on until the message was accessed) operated as a reminder.

Given the constraints of this experiment, the alerting issue will only be settled after further research has been completed. Since this study is part of a series of Data Link experiments that will eventually encompass oceanic and en route airspace, it will be useful to use the same alerting scheme in these environments to contrast the results with crew behavior in terminal airspace. Such work will help determine what type of alert is adequate for Data Link annunciation in all phases of flight. For example, the data from these studies may show that a general purpose auditory alert (such as SELCAL) produces acceptable pilot response times in terminal but not in en route airspace, because more company and cabin calls are experienced more frequently in the latter situation. Experiments are also being planned to evaluate other alerting schemes, such as digitized speech.

The second research question was: What is the acceptability of an aft-center pedestal-mounted CDU given head-up requirements of terminal operations? This issue is of interest because of the need to consider aft-CDU locations in order to retrofit some cockpits with Data Link. Although there is no item in [2] regarding display placement, this issue relates to section 3.2, "Flight Crew Response Time;" and section 5.2.5, "Head D own Time."

The third research question addressed presentation of incoming Data Link messages (section 5.2 .7 in [2]). There is interest in whether digitized speech announcement of D ata Link messages will result in reduced head downtime. The study compared three message presentation formats: radio-only, D ata Link text format, and Data Link text format plus digitized speech. 


\subsection{ATC SIMULATOR.}

The ART S IIIA laboratory at the FAA Technical Center was used to provide ATC for this study. The ARTS is a facility which uses actual National Airspace System (NAS) equipment to create a test bed capable of realistically exercising Data Link applications. The ART S Enhanced Target Generator (ETG) allows the system to act as functioning A TC simulator by providing radar data and radio inputs from simulation "pilots" (or "pseudopilots") operating from terminals in the laboratory.

The ART S laboratory is connected to a VAX 11/ 750 computer which acts as an emulation of the future ground Data Link processor. The VAX computer supports digital communication between simulation pilots and controllers. It provides two-way communication between controllers and high-fidelity aircraft simulators or actual airborne systems using Mode Select (Mode S) or any other installed Data Link technology. The VAX computer also carries navigation data from the remote simulators to the ART S in order to permit the display of aircraft targets on radar screens. At the time of this test, Data Link signal formats were not Radio Technical Committee for A eronautics (RTCA) SC-169 data dictionary compliant. Future studies will be compliant.

\section{$\underline{2.2 \quad \text { AIRCRAFT SIMULATOR SITES. }}$}

\subsubsection{Flight Simulators.}

A nalog cockpit transport category aircraft were employed in this evaluation. Two B-727-200s, one B-727-100, and one B-737-300 cockpit were networked into the test bed. Three of the four were equipped with Data Link annunciation lamps mounted under the glare shield, one prominent in the field of view of the left seat and one prominent in the field of view of the right seat.

Each cockpit had a Data Link CDU mounted in the center pedestal. Three cockpits had CDUs mounted forward of the throttles and one cockpit had the CDU placed behind the throttle quadrants. (This configuration of displays was dictated by technical problems that prevented mounting more than one display in the aft location.) Auditory alerting and speech production were provided by personal computer (PC) generated sounds played over a loudspeaker. All four analog cockpits were classified as phase II flight simulators [3].

It was recognized that there were some differences between B-727 and B-737 cockpits. Given the conditions of this experiment, no effect of cockpit on the main dependent measures of interest was anticipated.

\subsubsection{Data Link and Event Recording Equipment.}

At each simulator site, the Data Link CDU was connected to a PC that performed as a display driver and telephone circuit interface. Uplink and downlink Data Link communication with the FAA Technical Center was handled by this computer. The PC also functioned as a data logger and audio generator. It collected cockpit event data (CDU button presses and Data Link messages), time stamped each event (with 0.1-second precision), and stored the data onto hard disk storage media. It also provided the audio alerting (SELCAL) sound and digitized controller voice for the announcement of Data Link uplink messages.

\subsection{DISPLAYS.}

\subsubsection{Multifunction CDU.}

The display used was very similar in form, fit, and function to displays commonly used as FMC CDUs. It was a Honeywell model CD-800 which measured 6.8 inches high by 5.7 inches wide and fitted in standard Dzeus rail mountings. The display surface was 3.8 by 3.8 inches and displayed 9 lines by 24 columns of text in two fonts. A message recall switch (labeled "DIR") was mounted on the front bezel in the function key cluster. Brightness was 
continuously adjustable from full brightness to a minimum, but still viewable, level. Background illumination was controlled by the aircraft master dimmer circuit.

\subsubsection{Display Formats.}

Each uplink (except initial contact) required a WILCO or UNABLE response to complete the transaction. These responses were directly selectable by the CDU line select keys adjacent to the cathode ray tube (CRT). Messages in the message log were stored from most recent to oldest and were selectable using the line select keys. Messages were marked to indicate type, origin, and pilot response associated with each message. All functions were selectable from a top level menu.

\subsection{CREW ALERTING.}

\subsubsection{Auditory Alerting.}

A uditory alerting was provided by a "Pro Audio Spectrum 16" brand audio digitizer card installed in the Data Link PC at each simulator site. This card recorded audio and played it back under process control and was capable of 16-bit record and playback at a sampling rate of 2 to 44.1 kilohertz ( $\mathrm{kHz}$ ). Tones and speech were recorded at $11.5 \mathrm{kHz}$. Sounds were heard in each cockpit through a self-powered "SO NY" SRS-88 loudspeaker with user-controlled volume.

A SELCAL sound was recorded and played back as part of the alerting experimental factor. The SELCAL sound used in B-727 cockpits is usually a two-tone, mechanical doorbell chime. The same units are available for home use. The SELCAL sound used for this experiment was digitally recorded from a "Nutone" brand doorbell.

\subsubsection{Visual Alerting.}

Visual cues were provided by a combination of glare shield mounted, blue lens, aviation-type lamps and lighted message indicators on the CDU s or CDU lamps alone (depending upon experimental condition). All visual cues were illuminated as long as the current D ata Link message was pending. Glare shield lamps did not flash.

It was recognized that, in the experimental condition with a forward-mounted display and no glare shield light, pilots might detect the small D SPLY light on the Honeywell CDU (which should have been visible in their peripheral visual fields) on the CDU upon hearing the SELCAL sound. As a result, the forward field of view lamp may not have provided much additional benefit as a visual alert. However, it was expected that response time measurement would offer useful information on the need for an additional glare shield light.

The ART S IIIA Data Link software allowed for only one message transmission at a time. Pilots has to WILCO or UNABLE each ATC message before another could be transmitted. Therefore, during routine operations, it was not necessary to access the message log function of the CDU to read pending messages, nor was it necessary to maintain visual alerting until all messages were read.

\subsection{SPEECH PRODUCTION.}

Announcement of Data Link messages was provided by the same audio digitizer card and loudspeaker used for the Data Link alerting sound. A set of spoken Data Link message components were recorded by an air traffic controller and digitized on the hard disk of each remote simulator Data Link PC. These recordings were accessed by control software when Data Link messages were received from ATC. As with a text message, a D ata Link alert was activated and the pilot was required to press a key on the Data Link CDU to hear the message. The message simultaneously appeared in text format on the CDU. In both text-only and speech-with-text conditions, a WILCO or UNABLE response was then selected from the Data Link CDU. 
All subject pilots were typerated in the aircraft that they operated. All first officers were qualified (but not necessarily type-rated) in the specific aircraft. A captain and first officer (as opposed to two captains) flew in each crew. Captains and first officers were obtained with the cooperation of the Airline Pilots Association (ALPA). Participation from ATA and RTCA was also invited.

A policy of mixing of crews from different airlines was adopted because it placed all crews under the same starting conditions of not being familiar with each other's procedures. This required crews to agree upon basis flight procedures during the pre-experiment briefing.

The briefing covered a description of the experiment, use of cockpit checklists, airspace information, mission description, and Data Link procedures. Each crew was required for 1 day at a flight simulator location; 32 crews were used.

\section{EXPERIMENTAL DESIGN.}

\subsection{EXPERIMENTAL FACTORS DESCRIPTION.}

Three equipment-related independent variables were examined in a controlled experiment. These were crew alerting, display location, and message display. The experiment was divided into two parts, each considering two experimental factors (as shown in figure 1). Message display was common for all sites but display location and alerting were tested in separate pairs of simulators.

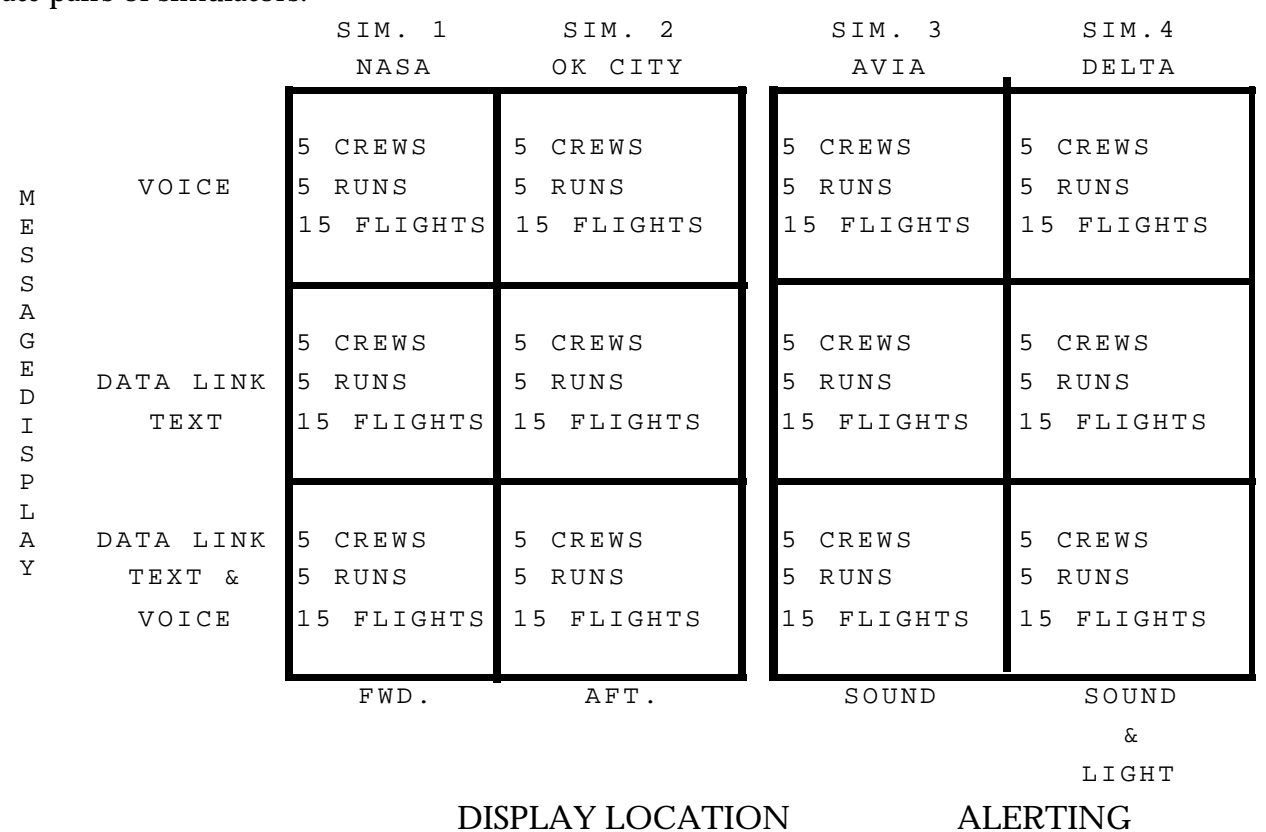

FIGURE 1. EXPERIMENTAL DESIGN 


\subsubsection{Crew Alerting.}

Coincident with the arrival of Data Link messages, flight crew attention was directed to the Data Link CHI by one of two alerts. Crew alert consisted of either SELCAL sound only or SELCAL sound combined with forward primary field of view visual alerting (a blue light mounted on the glare shield in front of each pilot). In both cases, a small light on the CDU illuminated at the same time as the other alerts. The visual alert was maintained as long as a Data Link message was pending. There were two levels in this factor; SELCAL sound only or SELCAL sound with glare shield light.

Crew alerting manipulations were carried out only in two simulators. To reinforce to subjects that SELCAL was a multipurpose cockpit annunciation sound, it was triggered for one other message during each flight. During each flight, the SELCAL sound was activated once at a point from 30 seconds to 4 minutes (selected on a random basis) after the second Data Link message was received. The crew had been previously instructed to ask the cockpit observer (who was also in the cockpit) for a preprinted company message which instructed them regarding a gate change. Crew alerting in the other two simulators was SELCAL sound with glare shield and CDU lights.

It was hypothesized that the addition of the blue glare shield annunciator light would significantly decrease crew response time to access the incoming message from the Data Link CDU as compared to an alert consisting of the SELCAL sound alone. It was also predicted that flight crews would prefer the unique alert. The difference in type of alerting was not expected to affect any other dependent measure.

\subsubsection{CDU Location.}

Display location was derived from a study that surveyed anticipated Data Link display locations in airline aircraft [4, 5]. The two most common locations were center pedestal forward and aft of the throttle quadrant. There were, therefore, two levels in this variable. CDU s were mounted in aft positions in one simulator and in forward positions in the other three simulators (as shown in figure 1).

It was expected that the aft-mounted display would require longer crew response times both for initial access of a pending Data Link message and for acknowledgment of the message with a WILCO or UNABLE. A second hypothesis was that the crews would indicate that the forward CDU location required less effort to operate and was preferable to an aft-mounted unit. The aft display location was also expected to require more crew attention (more head away time from primary instruments). No effects on other dependent measures were anticipated. 


\subsubsection{Message Display.}

Three experimental conditions were created concerning the method for displaying ATC instructions (as shown in figure 1). In one, the arrival of incoming Data Link messages was simultaneously announced by some combination of visual and auditory alerts. After pressing the DIR key on the CDU bezel, the Data Link message was displayed in text format. WILCO or UNABLE was then selected using other CDU keys.

In the second condition, the button press on the CDU activated a digitized air traffic controller's voice that spoke the message over a cockpit loudspeaker. Simultaneously, the D ata Link message text was displayed on the CDU. The aircrew was able to replay the speech message by pressing a key on the CDU. The WILCO or UNABLE response was made as in the text-only condition.

The third communication condition was radio-only. All ATC instructions were transmitted over the radio channel with no other visual or auditory alerting. Radio-only was included so that baseline data could be collected on pilot situation awareness (SA), communication activities, and workload. Accordingly, a proportion of the flights conducted by each flight simulator was with radio-only communication (the CDUs were turned off) and the rest involved primarily Data Link usage.

It was predicted that radio use when Data Link was available would be less than with radio alone. It was hypothesized that there would be no significant crew response time differences in accessing or responding to Data Link messages under the two types of Data Link presentation conditions. SA was predicted to decrease for D ata Link flights (as compared to radio-only) but with no differences for Data Link message presentation mode. It was expected that crews would prefer the digitized speech presentation over the text-only format but would prefer radio over Data Link, in general. No effects of communication method on other dependent measures were anticipated.

\subsection{TEST DESIGN.}

The message display factor had three levels and the alerting and display location factors each had two levels resulting in two, 3x2 mixed plot, factorial experimental designs. Figure 1 shows the four simulator configurations for alerting, location, and message display. The CDU location and alerting variables were between-subjects factors while the message display factor was within-subjects.

It should be noted that, although radio-only was listed as one of the levels of the message display factor, it was only included in order to collect baseline data on a subset of the dependent measures. The between-subjects factors of display location and auditory alerting were not relevant in radio-only conditions. The remaining paragraphs in this section describe the dependent measures and data collection methods. 


\subsection{NUMBER OF RUNS.}

Experimental trials were conducted for 8 days for 8 hours per day (including pilot training and debriefing). Prior to the first experimental run, a 20-minute D ata Link practice flight was completed without the simulators being on-line with the FAA Technical Center systems. Following this were three data collection runs. Each lasted 1-1/ 2 hours, resulting in three runs per day (with breaks). The order of the runs was counterbalanced to compensate for practice effects.

Five days of successful data collection were completed resulting in 15 runs per simulator site. Pilots flew a minimum of three arrival flights per run ${ }^{1}$ and alternated roles of pilot flying $(\mathrm{PF})$ and pilot not flying (PNF) between each flight. This created a total of at least 45 flights per site over the 5 days (depending upon simulator site). There were a minimum of 15 arrival flights in each cell of the design.

\subsection{DEPENDENT MEASURES.}

The dependent variables were:
a. Communication activity.
b. Situation awareness.
c. Subjective effort.
d. Data Link attention requirements.
e. Fuel Burn.
f. Subjective opinions regarding the cockpit Data Link interface, alerting methods, display location, and Data Link display mode.

\subsubsection{Communication Activity.}

Communication effort was assessed by measuring the total amount of time pilots spent using the very high frequency (VHF) radio and Data Link modalities. The PC processor at each simulator site collected cockpit event data. A video camera in each cockpit recorded crew activity.

Controller and pilot microphone use was recorded at the FAA 's A MECO M (a voice switching and recording system) through the active push-to-talk status word in the simulator data stream. Each message was time stamped to 1-second precision. Voice recordings of all controller and pilot interactions were also available from the AMECOM.

\footnotetext{
1 There were two types of arrival flights into the airspace differing in distance and time flown. Simulators were assigned to one type of route. One pair of simulators was able to fly three flights per run and the other pair completed four flights per run.
} 
Response time epochs were logged based on key events in the Data Link transaction. These were defined as follows and are shown in figure 2. Each event was recorded by the appropriate FAA Technical Center or remote simulator site computer.

Event 1: $\quad$ Incidence of crew alert announcing message pending. Event 2: $\quad$ Pilot pressed message key to call message to viewing

$$
\text { surface }
$$

Event 3: $\quad$ Pilot pressed WILCO / UNABLE key.

Event 4: $\quad$ Pilot made control input and the simulator responded.

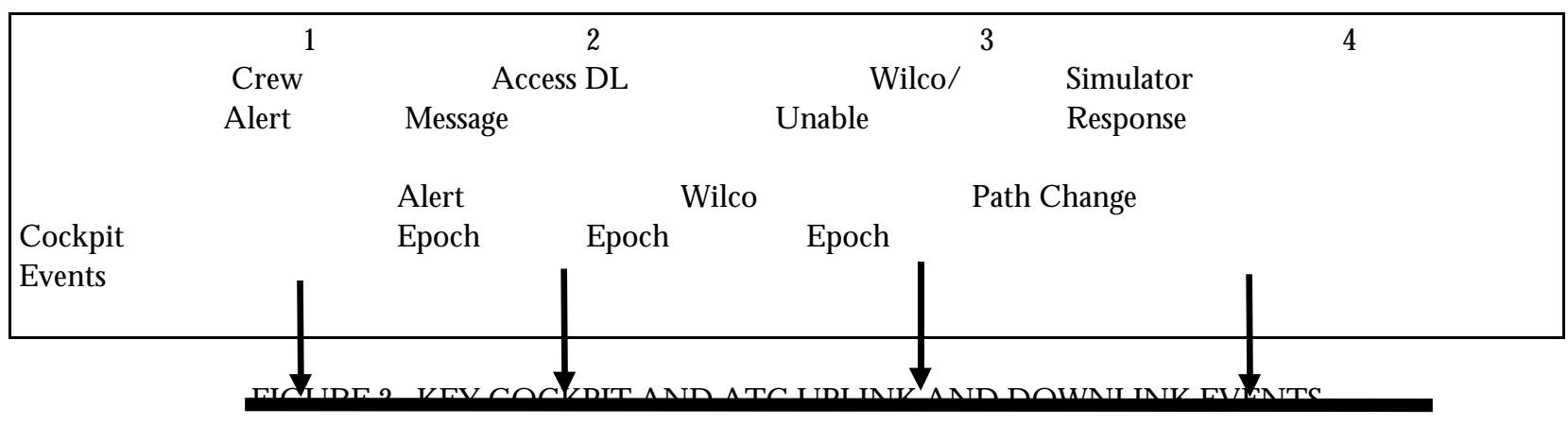

The time measurement epochs associated with each interval are:

Alert Epoch: Began with incidence of crew Data Link alert. Ended when pilot selected the message for display.

WILCO Epoch: Began with pilot selection of the message for display and ended with the selection of a WILCO or UNABLE response.

Path Change

Epoch:

Began with a pilot WILCO or UNABLE selection and

ended with a control input as indicated by

navigation data transmitted by the simulator.

(Navigation data was available from the ARTS

system.)

\subsubsection{Situation A wareness.}

There is concern on the part of the ATA that aircrew SA will be degraded by the removal of the radio "party line" as ATC communication shifts to Data Link [2]. In order to evaluate this concern empirically, aircrew SA was measured during both radio-only and Data Link runs.

There are a number of different kinds of party line information (PLI) gained from radio communication between ATC and aircraft and between aircraft. Midkiff and Hansman [6] conducted questionnaire research on important PLI elements. The items relating to terminal area and final approach are listed in table 1. Each SA component was evaluated to establish its source and whether, in the terminal environment used for this experiment, it would be degraded should an aircraft exclusively be using Data Link. As can be seen in table 1, a number of tower-related SA items were not relevant in this study because there was no tower ATC position and thus no tower Data Link services.

TABLE 1. SITUATION AWARENESS ITEMS

\begin{tabular}{|l|l|l|}
\hline \multicolumn{1}{|c|}{ SITUATION AWARENESS ITEM } & \multicolumn{1}{c|}{ SOURCE } & \multicolumn{1}{c|}{ AFFECTED? } \\
\hline NEXT COMM. FREQ UENCY & ARRIVAL/FINAL ATC & YES \\
\hline WEATHER SITUATION & ATIS & NO \\
\hline
\end{tabular}




\begin{tabular}{|l|l|l|}
\hline WEATHER SITUATION & AIRCRAFT & YES \\
\hline TRAFFIC SITUATION & ARRIVAL/FINAL ATC & YES \\
\hline SEQUENCING & ARRIVAL/FINALATC & YES \\
\hline HOLD SITUATION & ARRIVAL/FINAL ATC & NO \\
\hline TERMINAL ROUTING & ARRIVAL/FINAL ATC & YES \\
\hline APPROACH CLEARANCE & ARRIVAL ATC & YES \\
\hline CONTROLLER ERRORS & ARRIVAL/FINAL ATC & YES \\
\hline MISSED APPROACH & TOWER ATC & NO \\
\hline WINDSHEAR & AIRCRAFT & NO \\
\hline GO AROUND & AIRCRAFT/TOWER ATC & NO \\
\hline AIRCRAFT ON RUNWAY & NO \\
\hline BRAKING ACTION & AIRCRAFT/TOWER ATC & NO \\
\hline TAXIWAY TURNOFF & AIRCRAFT/TOWER ATC & NO \\
\hline
\end{tabular}

The items that were handled by the ART S IIIA Data Link message set related exclusively to terminal ATC instructions for altitude, course or speed changes, and runway clearances. Use of the Data Link medium for these messages could influence the traffic SA of pilots. O ther SA information, such as weather, was communicated using radio.

In a flight scenario where Data Link was the only medium for transmitting navigational instructions, pilot SA effects would be limited to a probable reduction in the understanding of the positions, movements, and plans of other aircraft relative to own ship. Consequently, this study focused on "traffic SA." However, there may have been indirect effects of Data Link use on weather awareness as well. If a pilot is not informed as to the relative positions of aircraft ahead, radio communications from these aircraft about inclement weather conditions may be heard, but not comprehended as relevant.

Endsley defined three levels of SA [7]. Level 1 involves the perception of situational elements or the important facts in the environment. In Level 2, "Information Integration," the operator determines the meaning of this information and then is able to generate Level 3 SA, "Projection of Future Status and Actions of Situational Elements." In this experiment, Levels 1, 2, and 3 SA were assessed by asking about surrounding aircraft, by observing pilot responses to a scripted weather problem, and by assessing attitudinal factors. 
A bout 2 minutes after having transferred to the west or east final controller, the PNF was asked to mark the location and altitude of nearby traffic on a simple map. (Pilots were allowed to collaborate about the map.) At the same point during other flights, three brief questions were asked of the aircrew (either pilot was allowed to answer). The questions were:

a. What aircraft is immediately ahead of you?

b. Name another aircraft at your altitude.

c. What order will you be in for final?

In order to compare pilot reports against the real ATC situation, a video camera recorded each run at an unoccupied workstation in the ARTS IIIA laboratory. This was sufficient to collect aircraft data in the final sectors. SA map comparison data was also available from ARTS IIIA computer files. The SA maps and probe questions were initiated by the cockpit observer. Responses were noted along with computer clock time.

A nother SA measure was problem-related. While in the arrival sector, the pseudopilot of the ARTS IIIA ETGgenerated aircraft closest to a flight simulator used radio to report turbulence. The cockpit observer noted whether the flight crew discussed the weather situation and if the location of the reporting aircraft was mentioned as a factor. It was assumed that if location was discussed, it might indicate a lack of pilot traffic SA .

Each of the preceding SA measures was used during one flight per run. O rder of presentation was counterbalanced.

A fourth type of SA measure focused on pilot attitudes. After each run, the site facilitator asked the pilots to complete a short questionnaire. Items included quality of communication, pilot confidence, amount of information available, planning capabilities, safety assessment, and comments.

\subsubsection{Subjective Effort.}

Different alerting, display location, and message presentation conditions may affect pilot effort. Effort was measured using the Modified Cooper-Harper Scale [8]. After each flight, the cockpit observer asked both members of the flight crew to note average effort level during the prior flight on four scales (workload, time busy, thinking, and stress).

\subsubsection{Data Link Attention Requirements.}

Accessing, reading, and responding to Data Link messages may distract pilots from other tasks and generally redirect their activity. In order to assess this, a video camera was positioned behind the pilots along the centerline of each cockpit. It was aimed to show the backs of the pilots heads, the glare shield Data Link annunciator lights, and the Data Link CDU. During each flight, a video record was made of pilot head and arm movements. As each Data Link message was received (as marked by the activation of the SELCAL sound), PF and PNF activity was observed and recorded. Videotapes were later analyzed to determine the nature of crew attention to the Data Link CDU.

\subsubsection{Fuel Burn.}

Each simulator site had the capability to measure fuel used. Fuel burn was measured from the time of release from the insertion point until touchdown. This was recorded by the cockpit observer after each flight.

\subsubsection{Q uestionnaire Data.}

At the end of each day, pilots were asked to respond to questions regarding the usability of the Data Link interface and to offer feedback regarding cockpit Data Link implementation.

\subsection{ATC MESSAGES.}

The ATC message set consisted of the following Data Link message types: terminal information (TI), menu text (MT), and transfer of communication (TC). A randomly selected simulated uplink delay time of 0 to 4 seconds was used with 
all Data Link messages. In the radio-only runs, ATC instructions consisted of typical voice transactions for the terminal area.

\subsection{FLIGHT SCENARIOS.}

O ne basic flight scenario was written for the experiment and each aircrew experienced it three times (twice in the Data Link conditions and once in the radio condition). Aircraft identifiers were varied between runs to reduce the chance that pilots would be able to remember aircraft around them. A ircraft targets were generated by the ARTS IIIA ETG system and by the four remote flight simulators. Scenarios were designed to operate with an instantaneous traffic load of approximately 5 to 8 aircraft in each of the two sectors (arrival and final) per side of the airspace (east and west).

Runs lasted 1-1/ 2 hours each with three or four arrival flights per run. Aircraft were 100 percent radio (no Data Link) in the radio-only communication condition, and a mixture of 80 percent Data Link and 20 percent radio equipped in the D ata Link communication conditions. Flight simulators were always D ata Link equipped in D ata Link runs. Data Link aircraft were permitted to use radio communication during D ata Link runs. This resulted in a decrease, but not elimination of radio messages in the Data Link conditions.

The rationale for a mixture of Data Link and radio-only aircraft and allowing controllers to use radio in Data Link conditions was that it was more like the anticipated real-world situation. There will continue to be (for the foreseeable future) non-D ata Link aircraft, and controllers will not be restricted to using Data Link. Even under these conditions, there was a substantial reduction in radio traffic in the Data Link experimental conditions.

Flights were conducted in the Raleigh-D urham terminal airspace. Conditions were instrument flight rules (IFR) with 1,000-foot ceiling and 3-miles visibility. Flight simulators and computer generated ETG aircraft flew downwind or near straight-in approaches to both runways. No departures were flown. Flight simulators were assigned to one type of approach and alternated runways. This resulted in a complete set of data for all approach types for any given between- or within-subjects comparison.

Crews were permitted to hand-fly or use the autopilot for flying approaches. Crew choice of flying mode was recorded by the cockpit observer.

\subsection{SUPPORT PERSO NNEL.}

In the ARTS IIIA laboratory, four air traffic controllers from the Air Traffic Data Link Verification Team (ATDLVT) were recruited to act as controllers. Local pilots were trained in the operation of the ART S IIIA ETG pilot terminal and acted as pseudopilots. Additional personnel were needed in the ARTS IIIA laboratory to act as Data Link terminal operators. These individuals were FAA or CTA, Inc., staff.

A site coordinator and cockpit observer were stationed at each remote simulator location. It was the coordinator's responsibility to ensure that the subject pilots arrived on time and at the proper location. The coordinator (a pilot) greeted visiting pilots and provided an orientation briefing and training session. The observer rode "jump seat" during the missions to gather data, as required. This person also served to answer any pilot questions once the mission had begun. A local technician or other assistant handled communication with the FAA Technical Center and other tasks required to conduct the simulation.

\subsubsection{Training O rientation.}

When each crew arrived at a simulator site (1-1/ 2 hours before the first flight), the site coordinator provided a briefing on the goals of the experiment, airspace characteristics, operation of the Data Link cockpit interface, and cockpit procedures. Pilots were able to exercise the $\mathrm{D}$ ata Link communication system by invoking a self-test function. This permitted them to display and respond to a set of typical Data Link messages. Following this, an off-line Data Link simulator practice arrival flight of 20-minutes duration was completed to allow crews to practice cockpit and Data Link procedures. 
Data Link data from flight simulators was recorded on computer diskettes in IBM PC compatible format. The disk files held logs of all Data Link messages, all keystrokes, and time events as described in section 4.4.1. In addition, the ART S processor provided information on simulator navigation, and the AMECO M system recorded voice transactions. There was also data from questionnaires and videotapes as collected by site personnel.

\section{RESULTS.}

O utcomes are discussed with reference to the set of dependent measures described in section 4.4. Findings relevant to the three variables of interest: crew alerting, CDU location, and message display, are discussed for each dependent variable. Means and statistics for tests of significance are reported, where relevant. Interactions between variables are not mentioned or reported, unless statistically significant. Assumptions for statistical tests used were checked and were satisfied, unless specifically discussed.

The Hyunh-Feldt adjustment for degrees of freedom in within-subjects designs was applied when indicated (Howell, 1987). An analysis of variance (ANOVA) probability (p) value of 0.05 was chosen as the cutoff for statistical significance. Therefore, any results in the following sections or tables that show a "p" of less than .05 were considered statistically significant.

Given the experimental design, practice effects can affect the results. Steps were taken to examine these effects and remove them from the analysis, if necessary (Keppel, 1982).

\subsection{COMMUNICATION ACTIVITY.}

Data were gathered on the frequency and duration of Data Link and radio communication. However, the focus of communication activity measures was on pilot response time to Data Link messages. As noted in section 4.4.1, there were three epochs of interest. These were called the "Alert Epoch," "Response Epoch," and "Path Change Epoch."

\subsubsection{Frequency and Duration of Communication.}

Data extraction software was written to access information about controller and pilot radio communication from the A MECO M system. Push-to-talk actions within the ARTS laboratory were captured. These data were analyzed to study the effects of communication type on controller radio activities. Given that the controller was one end of a twoway transaction, these results indirectly reflected pseudopilot and simulator pilot radio activity. The number of pushto-talk events by controllers during a 1-1/ 2 hour run were nearly the same under both Data Link conditions and were much higher for radio-only. Likewise, the total duration of radio transmissions by controllers to pseudopilots and simulator pilots was over three times as long as with Data Link. The average duration of each message, however, was not significantly different across communication conditions. The data are shown in table 2.

\section{TABLE 2. CONTROLLER COMMUNICATION ACTIVITIES}

\begin{tabular}{|l|r|r|r|r|r|r|}
\cline { 2 - 7 } \multicolumn{1}{c|}{} & \multicolumn{4}{c|}{ Communication Type } & \multicolumn{1}{c|}{ ANOVA Statistics } \\
\hline \multicolumn{1}{c|}{ Measure } & \multicolumn{1}{c|}{ Radio } & DL Speech & DL Text & \multicolumn{1}{c|}{$\mathrm{df}$} & \multicolumn{1}{c|}{$\mathrm{p}$} \\
\hline PTT Actions & 183.7 & 48.8 & 45.0 & 2,32 & 275.7 & .0001 \\
\hline Duration & 724.1 & 190.6 & 183.8 & 2,32 & 274.3 & .0001 \\
\hline Mess.Length & 4.0 & 3.9 & 4.1 & 2,32 & 0.3 & .7113 \\
\hline
\end{tabular}

\subsubsection{Data Link Response Times.}

\subsubsection{Alert Epoch.}

The average crew response time data for the epoch starting with message annunciation and ending with pressing of the DIR key (to access the Data Link message) were relevant both to the display location and crew alerting questions. 
There was interest in whether a forward field of view light in addition to a standard SELCAL sound (the "unique alert") as opposed to a SELCAL sound alone (the "nondistinctive alert") would affect pilot response times when cockpit CDU s were forward-mounted. The effect of display location (forward versus aft of the throttle quadrants) on response time to the Data Link alert was tested in cockpits with unique alerting. The same data were also analyzed for Data Link communication type (text-only and text with speech).

The average response time for the unique alert was 2.8 seconds and for the nondistinctive alert was 2.7 seconds. An ANOVA was used to test the difference between the means and was not significant, $F(1,18)=0.36, p=.5574$. Mean response time when the display was aft-mounted was 2.9 seconds and 2.5 seconds for the forward mounting location. This time difference was statistically significant, $F(1,18)=17.6, p=.0005$.

The results for Data Link communication condition were that the alert epoch averaged 2.7 seconds for both Data Link text-only and digitized speech presentations, $\mathrm{F}(1,36)=0.97, \mathrm{p}=.9666$. Thus, there was no significant difference in pilot response time to a Data Link alert between text-only and digitized speech modes.

\subsubsection{WILCO Epoch.}

This response time epoch began with display of the D ata Link message (pressing the DIR key) and ended with pressing WILCO. It was not expected that there would be any effect of type of crew alerting on WILCO times. It was anticipated that the location of the Data Link CDU would affect this epoch but that method of display would have no effect.

The data for type of crew alerting showed a significant difference between simulator sites. The average WILCO response time for the unique alert was 10.2 seconds and for the nondistinctive alert was 8.6 seconds. The test of significance was $\mathrm{F}(1,18)=4.82, \mathrm{p}=.0415$. It was suspected that this difference was not due to the alerting condition, but to another unique situation in one of the cockpits that involved instructions to the flight crews to WILCO before making changes to the flight controls. This is discussed further in section 6.1.

When the response time data for CDU location were analyzed, it was discovered that there was no significant difference in time to respond to D ata Link messages between forward- and aft-mounting locations. The average WILCO time for the forward-mounted CDU was 10.2 seconds and for the aft-mounted CDU was 8.8 seconds. ANOVA results were $F(1,18)=3.67, p=.0714$. Although there was an average 1.4 seconds difference in response times, this may not be meaningful due to the variability in the data.

A cross all cockpits, there was a statistically significant difference in WILCO times for Data Link display conditions (text-only versus text with digitized speech). The average time for Data Link text-only was 8.7 seconds and for Data Link with speech was 10.1 seconds, $F(1,36)=27.34, P=.0001$.

It was also found that there was a significant difference in the length of time to WILCO for different types of Data Link messages. The averages for MT, TI, and TC messages were 8.7 seconds, 10.5 seconds, and 9.2 seconds, respectively, F(2, $72)=15.67, \mathrm{p}=.0001$. The results are graphed in figure $3 .{ }^{1}$

\subsubsection{Path Change Epoch.}

The third response time epoch focused on the point at which the simulator made a detectable heading, altitude, or speed change in response to a D ata Link message. These data were accessed from the ARTS data base of navigational information collected during the experimental trials and from the D ata Link messages recorded in the PCs at each simulator site. (A nalysis of the radio condition was not possible due to the fact that their was no log file for air crew radio message responses or response times.)

\footnotetext{
1 It is not advisable to conduct post hoc tests when dealing with repeated measures and therefore none of these tests were conducted for these data.
} 
The first step in the analysis involved the extraction of the controller Data Link messages and WILCO times to these messages for all flight simulators. This was done for both TI and MT messages. TC messages were excluded from this analysis since the content of the TC message never involved an instruction to change the aircraft path. Altitude, heading, and speed change messages were extracted from the flight simulator log files along with the ARTS time associated with the receipt and WILCO of these messages. (ARTS time refers to the time during the scenario when the command occurred. This was always between 12:00 and 13:30 and was recorded to the nearest tenth of a second.) O ther information including the specific flight simulator was also extracted.

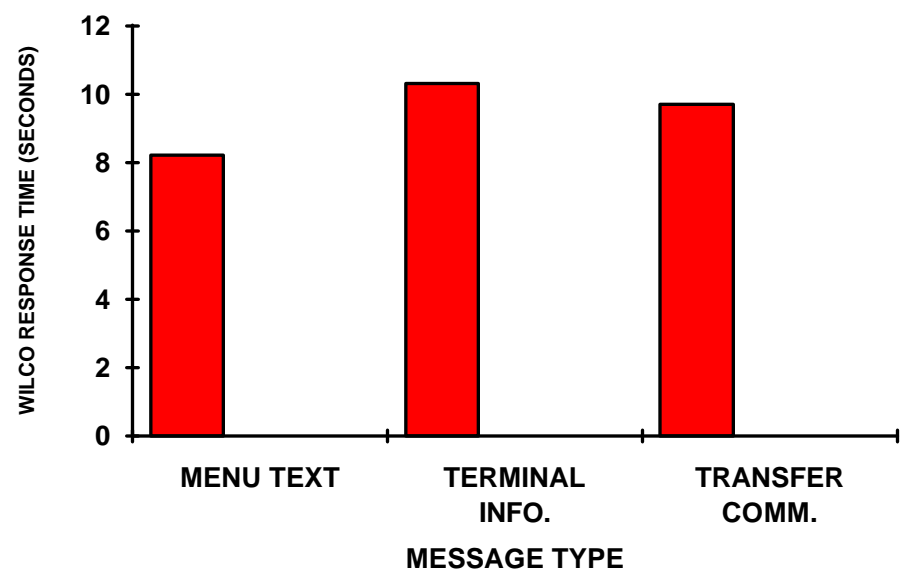

FIGURE 3. GRAPH OF WILCO RESPONSE TIMES

The second step in the analysis involved processing of the actual path change data. These data were recorded in the ARTS database for all flight simulators during testing. The files for all flight simulator runs were extracted and put into an ASCII format which then could be analyzed using a PC program. A software program was developed which took the times of the Data Link messages described previously and correlated these messages with the actual flight simulator path changes. A time was then recorded when the program detected the start of the aircraft path change.

Altitude, heading, and speed information were analyzed independently due to the fact that the controller could issue an altitude, heading, or speed change separately or in combination. Times were recorded to the nearest tenth of a second. However, due to the update rate of the radar, the accuracy of the path change times was limited to plus or minus 4.5 seconds.

The third step in the analysis was the creation of a path change epoch. This involved referencing the time of the aircraft path change to the time the aircraft command was WILCO ed. This was done to measure the path change epoch described earlier in the report and in the Data Link test plan. Positive path change times indicated that the path change occurred after the air crew WILCO ed the ATC command. Negative path change times indicate that the path change occurred before the WILCO was issued.

The fourth step involved statistical comparisons of path change epochs for simulator site and Data Link communication condition. Comparisons were made only for altitude and heading changes. Speed changes were not included due to the fact that the speed for most simulators changed virtually continuously, thus it was extremely difficult to discern when a speed change started in response to an ATC instruction. This was also true for altitude changes, but to a much lesser degree. Path changes that were not detectable were treated as missing data.

A comparison made between simulators with the two different types of crew alerting showed no significant difference in path change epochs for either heading or altitude $D$ ata Link messages. There was also no significant difference in path change times for heading or altitude as a function of CDU location. Likewise, there were no significant differences in path change times for communication condition. The averages and ANOVA test data are shown in tables 3,4 , and 5 . 
TABLE 3. PATH CHANGE EPOCH TIMES FOR TYPE OF CREW ALERT

\begin{tabular}{|l|l|c|c|c|c|}
\cline { 2 - 6 } \multicolumn{1}{c|}{} & Crew Alert & \multicolumn{3}{c|}{ ANOVA Statistics } \\
\hline Measure & ND & Unique & $\mathrm{df}$ & $\mathrm{F}$ & $\mathrm{p}$ \\
\hline Heading & 14.4 & 11.1 & 1,18 & 1.02 & .3263 \\
\hline Altitude & 11.8 & 13.4 & 1,18 & 0.44 & .5158 \\
\hline
\end{tabular}

TABLE 4. PATH CHANGE EPOCH TIMESFOR CDU LOCATION

\begin{tabular}{|l|l|c|c|c|c|}
\cline { 2 - 6 } \multicolumn{1}{c|}{} & \multicolumn{2}{c|}{ Crew Alert } & \multicolumn{4}{c|}{ ANOVA Statistics } \\
\hline Measure & Aft. & Fwd. & df & F & p \\
\hline Heading & 11.7 & 15.1 & 1,18 & 0.89 & .3587 \\
\hline Altitude & 15.3 & 10.0 & 1,18 & 1.93 & .1818 \\
\hline
\end{tabular}

TABLE 5. PATH CHANGE EPOCH TIMES FOR COMMUNICATION TYPE

\begin{tabular}{|l|c|c|c|c|c|}
\cline { 2 - 7 } \multicolumn{1}{c|}{} & Communication Type & \multicolumn{4}{c|}{ ANOVA Statistics } \\
\hline Measure & DL Speech & DL Text & df & F & p \\
\hline Heading & 14.2 & 11.9 & 1,36 & 0.80 & .3770 \\
\hline Altitude & 11.0 & 14.2 & 1,18 & 2.62 & .1144 \\
\hline
\end{tabular}

As can be seen from the data, detectable simulator path changes occurred on the average about 13 seconds after the WILCO response was recorded. A small number (about 10 percent) of these heading and altitude path changes happened prior to the WILCO response.

\subsection{SITUATION AWARENESS}

SA was assessed using four techniques. The reason for considering SA in this study was to determine if there was a measurable significant reduction in pilot awareness in Data Link conditions as opposed to radio-only conditions. It was not expected that the other independent variables (CDU location and crew alerting method) would have any effect on SA, and therefore no analyses were performed.

\subsubsection{Problem Weather.}

During one flight each run, one of the pseudopilots in the same sector as one of the simulators reported turbulence. Cockpit observers noted whether the crew made any response to each report and specifically whether any of the discussions focused on the location of the reporting aircraft. Table 6 shows the percentage of flights that the crew discussed the weather report or made any queries about it. Also shown in this table is the percentage of these flights where the location of the reporting aircraft was mentioned or queried. Although it appears from figure 4 that there were differences between some of communication modes, statistical tests indicated no significant differences, (DL Speech vs. DL Text (discussion):

$\chi 2(1, \mathrm{~N}=35)=0.26, \mathrm{p}>, 05$; (location): $\chi 2(1, \mathrm{~N}=35)=2.34, \mathrm{p}>, 05 ; \mathrm{DL}$ vs. Radio (discussion): $\chi 2(1, \mathrm{~N}=35)=$ $0.64, \mathrm{p}>, 05$; (location): $\chi 2(1, \mathrm{~N}=35)=0.44, \mathrm{p}>, 05)$.

TABLE 6. PERCENT OF FLIGHTS CREW DISCUSSED

\begin{tabular}{|l|c|c|}
\hline Comm. Type & Discussion & Location \\
\hline DL Speech & 44.4 & 22.2 \\
\hline DL T ext & 58.5 & 52.9 \\
\hline DL Both & 51.4 & 37.1 \\
\hline
\end{tabular}




\begin{tabular}{|l|c|c|}
\hline Radio-O nly & 35.3 & 23.5 \\
\hline
\end{tabular}

Figure 4 suggests that there tended to be slightly more discussions regarding the bad weather report in Data Link conditions as compared to radio-only, with the largest difference appearing for Data Link text-only. If there was a discussion, the reporting aircraft's position was mentioned most frequently with Data Link text-only communication.

\subsubsection{Maps.}

Shortly after each flight simulator entered the final sector on one flight each run, a map was given to the PNF. Information was requested regarding other aircraft within a 15-mile radius (altitude, heading, speed, azimuth, and distance). The data recorded on each map was compared with videotape of the ART S radar screen. A set of criteria were established with which to score the results, as follows:
Altitude
Within 1000 feet (plus or minus)
Heading
Within $10^{\circ}$ (plus or minus)
Bearing (to other aircraft) Within $10^{\circ}$ (plus or minus)
Distance
Speed
Identifier
Within $2.5 \mathrm{mi}$ (plus or minus)
Within 50 knots (plus or minus)
Company Name

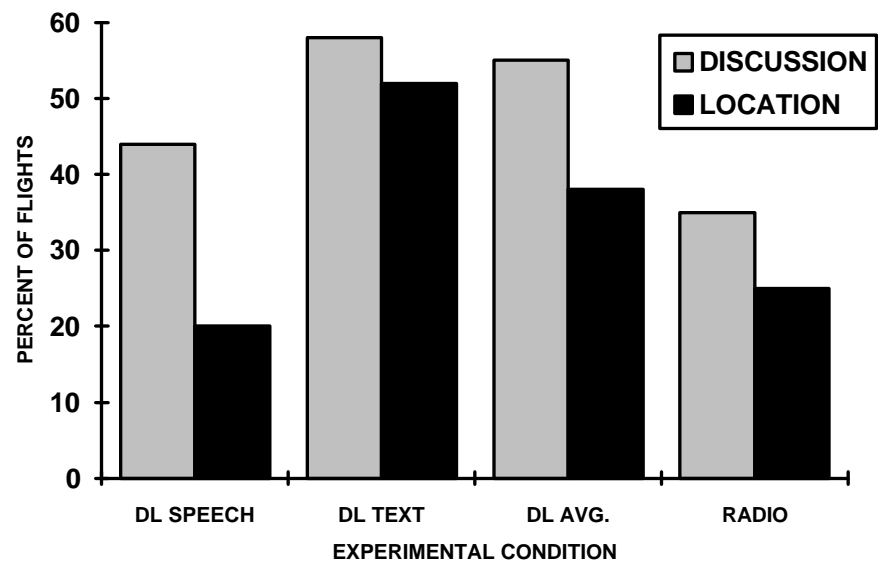

FIGURE 4. CREW RESPONSESTO BAD WEATHER REPORT

Table 7 presents the number of aircraft identified per flight for each type of run (radio-only, Data Link with speech, and Data Link text-only), the number of pieces of information noted on maps per flight, and the number of items that were correct. ${ }^{1}$ There were more aircraft recorded correctly in radio-only condition than in either Data Link condition. A graph of the items recalled and correct appears in figure 5.

TABLE 7. NUMBER OF AIRCRAFT AND ITEMS RECALLED PER FLIGHT

\begin{tabular}{|l|c|c|c|}
\hline Comm. Type & $\begin{array}{c}\text { Aircraft } \\
\text { Recalled }\end{array}$ & $\begin{array}{c}\text { Items } \\
\text { Recalled }\end{array}$ & $\begin{array}{c}\text { Items } \\
\text { Correct }\end{array}$ \\
\hline DL Speech & 0.2 & 0.6 & 0.4 \\
\hline DL Text & 0.3 & 1.2 & 1.0 \\
\hline DL Average & 0.3 & 0.9 & 0.7 \\
\hline Radio-O nly & 0.8 & 3.0 & 2.3 \\
\hline
\end{tabular}

1 One point was given for a correct response even though it might have been correct for more than one aircraft. 


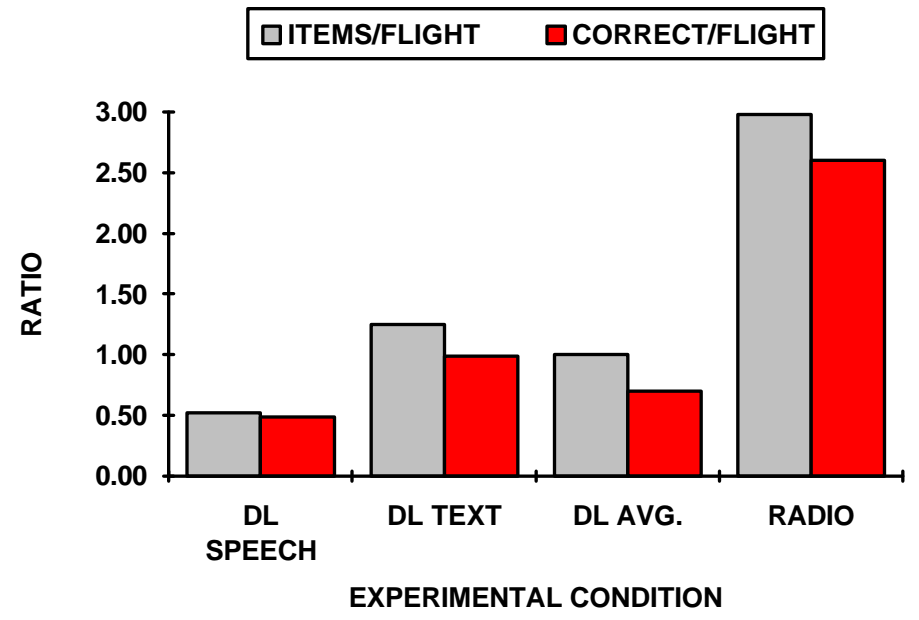

FIGURE 5. MAP SITUATION AWARENESS DATA

\subsubsection{Probe Questions.}

A nother technique for assessing situation awareness under radio and D ata Link conditions was to ask the pilots a series of three probe questions in the final sector. These were:

a. What aircraft is immediately ahead of you?

b. Name another aircraft at your altitude.

c. What order will Y ou be in for final?

The total number of correct answers for all three questions was scored using the same criteria (as relevant) applied to the map data. Table 8 summarizes the results and figure 6 shows a graph of the data. A gain, there were more correct responses in radio-only runs.

TABLE 8. PILOT ANSWERSTO PROBE QUESTIONS

\begin{tabular}{|l|c|c|}
\hline Comm. Type & Answers & Correct \\
\hline DL Speech & 1.4 & 0.4 \\
\hline DL Text & 1.0 & 0.2 \\
\hline DL Average & 1.2 & 0.3 \\
\hline Radio-Only & 2.0 & 1.0 \\
\hline
\end{tabular}




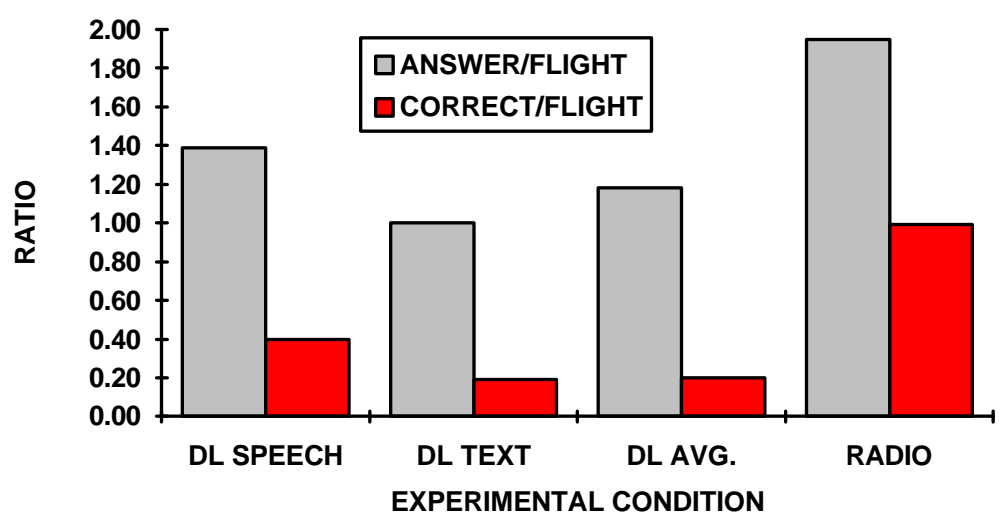

FIGURE 6. PROBE QUESTION SITUATION AWARENESS DATA

\subsubsection{Q uestionnaire Responses.}

Participants also filled out an SA questionnaire pertaining to their use of Data Link in the terminal environment. The questions dealt with the effect of communication method (radio versus Data Link) on their SA of the terminal environment. Table 9 shows the means and results of statistical tests for the items that dealt with the aircrew's SA when using Data Link. The results indicate higher ratings for all items when the aircrews used radio for ATC communication. All statistical tests were significant.

\section{TABLE 9. SITUATION AWARENESS Q UESTIO NNAIRE ITEMS (0 to 5 SCALE)}

\begin{tabular}{|c|c|c|c|c|c|}
\hline & Communication Type & & VA Stat & & \\
\hline Measure & Radio & Data Link & $\mathrm{df}$ & $\mathrm{F}$ & $\mathrm{p}$ \\
\hline Weather & 3.6 & 1.8 & 1,36 & 51.0 & .0001 \\
\hline A/C Separation & 3.4 & 1.5 & 1,36 & 109.8 & .0001 \\
\hline $\begin{array}{l}\text { Anticipate } \\
\text { Instructions }\end{array}$ & 3.8 & 2.1 & 1,36 & 59.7 & .0001 \\
\hline $\begin{array}{l}\text { Anticipate } \\
\text { Clearances }\end{array}$ & 3.7 & 2.4 & 1,36 & 34.7 & .0001 \\
\hline $\begin{array}{l}\text { Anticipate Next } \\
\text { Agency }\end{array}$ & 4.0 & 2.2 & 1,36 & 68.2 & .0001 \\
\hline Landing Sequence & 3.5 & 1.7 & 1,36 & 92.6 & .0001 \\
\hline
\end{tabular}

The positive aspects of using Data Link services most commonly cited were the ability visually to check clearances, frequency changes, headings, and altitudes and the advantage of working in a quieter, less distracting environment. The negative aspects of Data Link were identified as the increased workload involved in making frequency changes (which demanded more head-down time) and the restriction in the flow of information from the radio "party line" (distance from other aircraft and/ or final approach fix, weather reports, etc.).

Pilots were asked to comment on the effect Data Link had on their ability to detect potential controller errors. Of the 38 pilots who responded, 22 (58 percent) said Data Link decreased their ability, 4 (11 percent) said Data Link had no effect, 9 (24 percent) said Data Link increased their ability, 1 (3 percent) was uncertain, and 2 did not answer the question.

\subsection{SUBJECTIVE EFFORT.}

A subjective effort scale was administered to both members of the flight crew immediately after each flight. It was composed of four scales including workload, time busy, amount of thinking and planning, and amount of stress. Effort 
results are reported for each of the experimental factors. Data are also categorized by PNF and PF. It was assumed that the PNF's effort evaluations were most relevant for Data Link given that the PNF had the responsibility for interacting with the cockpit CDU. However, the PF's effort ratings were also be analyzed to consider other possible effects of the various Data Link conditions.

\subsubsection{Crew Alert.}

The pilots flying the simulators with unique and nondistinctive crew alerting were asked to evaluate effort on the four questionnaire scales after each flight.

\subsubsection{Pilot Not Flying.}

There were no significant differences in any PNF effort measure as a result of the type of crew alerting. The means and ANOVA results are found in table 10.

TABLE 10. SUBJECTIVE EFFORT FOR PNF FOR CREW ALERT FACTOR

\begin{tabular}{|l|c|c|c|c|c|}
\cline { 2 - 6 } \multicolumn{1}{c|}{} & Crew Alert & \multicolumn{4}{c|}{ ANOVA Statistics } \\
\hline Measure & ND & Unique & df & F & p \\
\hline Workload & 2.83 & 3.5 & 1,18 & 2.63 & .2185 \\
\hline Time Busy & 4.55 & 3.6 & 1,18 & 1,18 & .1031 \\
\hline Thinking & 4.12 & 3.6 & 1,18 & 0.75 & .3978 \\
\hline Stress & 3.77 & 3.6 & 0.04 & .8539 \\
\hline
\end{tabular}

ND - Nondistinctive

\subsubsection{Pilot Flying.}

There were no significant differences in any effort measure in the PF data as a result of crew alerting type. Means for each effort measure and ANOVA statistics were presented in table 11. 
TABLE 11. SUBJECTIVE EFFORT FOR PF FOR CREW ALERT FACTOR

\begin{tabular}{|l|c|c|c|c|c|}
\cline { 2 - 6 } \multicolumn{1}{c|}{} & Crew Alert & \multicolumn{4}{c|}{ ANOVA Statistics } \\
\hline Measure & ND & Unique & df & F & p \\
\hline Workload & 3.06 & 3.6 & 1,18 & 1.07 & .3140 \\
\hline Time Busy & 4.49 & 3.8 & 1,18 & 1.81 & .1959 \\
\hline Thinking & 4.27 & 3.7 & 1,18 & 1.16 & .2964 \\
\hline Stress & 3.80 & 3.8 & 1,18 & 0.00 & .9908 \\
\hline
\end{tabular}

\subsubsection{Display Location.}

The pilots flying the simulators with forward and aft-mounted Data Link CDUs were asked to evaluate effort on the four questionnaire scales after each flight.

\subsubsection{Pilot Not Flying.}

The only significant result emerging from the PNF data was that higher effort was associated with the aft-mounted display. (It should be noted that the other effort measures approached significance at $p<.05$ ). Means for each effort measure and ANOVA statistics are presented in table 12.

TABLE 12. SUBJECTIVE EFFORT FOR PNF FOR DISPLAY LOCATION FACTOR

\begin{tabular}{|l|c|c|c|c|c|}
\cline { 2 - 6 } \multicolumn{1}{c|}{} & CDU Location & \multicolumn{4}{c|}{ ANOVA Statistics } \\
\hline Measure & Aft. & Fwd. & df & F & p \\
\hline Workload & 4.4 & 3.2 & 1,18 & 4.94 & .0392 \\
\hline Time Busy & 4.6 & 3.5 & 1,18 & 3.34 & .0843 \\
\hline Thinking & 4.4 & 3.3 & 1,18 & 3.80 & .0671 \\
\hline Stress & 4.4 & 3.3 & 1,18 & 3.96 & .0620 \\
\hline
\end{tabular}

\subsubsection{Pilot Flying.}

There were no significant differences in any effort measure in the PF data as a function of the location of the Data Link CDU. Means for each workload measure and ANOVA statistics are shown in table 13.

TABLE 13. SUBJECTIVE EFFORT FOR PF FOR DISPLAY LOCATION FACTOR

\begin{tabular}{|l|c|c|c|c|c|}
\cline { 2 - 6 } \multicolumn{1}{c|}{} & \multicolumn{1}{c|}{ CDU Location } & \multicolumn{4}{c|}{ ANOVA Statistics } \\
\hline Measure & Aft. & Fwd. & df & F & p \\
\hline Workload & 4.54 & 3.6 & 1,18 & 2.36 & .1420 \\
\hline Time Busy & 5.00 & 4.5 & 1,18 & 18 & .4941 \\
\hline Thinking & 4.54 & 3.7 & 1,18 & 1.88 & .1868 \\
\hline Stress & 4.33 & 3.6 & 1,18 & 1.41 & .2500 \\
\hline
\end{tabular}

Communication Type.

Subjective effort was also analyzed as a function of communication mode (radio-only, Data Link text, and Data Link with digitized speech). Results were broken down into sets for PNF and PF. Table 14 shows the PNF effort data for all simulator locations. There were no differences for any of the subjective effort measures across communication types.

TABLE 14. SUBJECTIVE EFFORT FOR PNF AS A FUNCTION OF COMMUNICATION TYPE 


\begin{tabular}{|l|c|c|c|c|c|c|}
\hline Measure & Radio & DL Speech & DL Text & $\mathrm{df}$ & $\mathrm{F}$ & $\mathrm{p}$ \\
\hline Workload & 3.4 & 3.4 & 3.6 & 2,72 & 0.38 & .6861 \\
\hline Time Busy & 4.1 & 4.1 & 3.9 & 2,72 & 0.35 & .7067 \\
\hline Thinking & 3.9 & 3.8 & 3.9 & 2,72 & 0.10 & .9016 \\
\hline Stress & 3.9 & 3.6 & 3.8 & 2,72 & 0.43 & .6557 \\
\hline
\end{tabular}

Table 15 shows the PF effort data for all simulator locations. Again, there were no significant differences between communication types on any of the subjective effort measures.

\section{TABLE 15. SUBJECTIVE EFFORT FOR PF ASA FUNCTION OF COMMUNICATION TYPE}

\begin{tabular}{|l|c|c|c|c|c|c|}
\cline { 2 - 7 } \multicolumn{1}{c|}{} & \multicolumn{3}{c|}{ Communication Type } & \multicolumn{2}{c|}{ ANOVA Statistics } \\
\hline Measure & Radio & DL Speech & DL Text & df & F & p \\
\hline Workload & 3.4 & 3.7 & 4.0 & 2,72 & 2.24 & .1132 \\
\hline Time Busy & 4.4 & 4.4 & 4.5 & 2,72 & 0.23 & .7960 \\
\hline Thinking & 3.9 & 4.1 & 4.2 & 2,72 & 0.64 & .5299 \\
\hline Stress & 3.7 & 3.8 & 4.1 & 2,72 & 1.01 & .3679 \\
\hline
\end{tabular}

\subsection{DATA LINK ATTENTION REQUIREMENTS.}

Review of the cockpit videotapes yielded a number of kinds of useful information relating to the display of Data Link messages with or without digitized speech. These are divided into activities of the PNF and PF in attending to and acting on Data Link transmissions. Actions recorded included pilot glance at the Data Link CDU, length of glance, reading of messages ${ }^{1}$, and speaking messages. The factors of display location, crew alerting, and communication type are discussed, as relevant. See appendix A for a complete description of how the attention factors were measured.

1 A crew member was counted as having read a message if there was any subsequent action that clearly indicated use or comprehension of the displayed information. 


\subsubsection{Crew Alert.}

\subsubsection{Pilot Not Flying.}

Part of the workload associated with text display of Data Link messages is in crew coordination and cross-checking. It was assumed (and supported by videotape analysis) that for all practical purposes the PNF always glanced at the D ata Link CDU to access a message after the crew alert had been detected. This was necessary to guide hand and finger movement to the DIR key on the display. Therefore, no results are shown for PNF glance at the CDU (the effect of communication type have been removed from these analyses).

For the cockpits with different alerting systems, there were no significant effects of alerting type on how often the PNF appeared to read the message (as evidenced by subsequent actions) or spoke it out loud. These data are shown in table 16.

TABLE 16. PERCENT OF TOTAL DATA LINK MESSAGES

\begin{tabular}{|l|c|c|c|c|c|}
\cline { 2 - 6 } \multicolumn{1}{c|}{} & Crew Alert & \multicolumn{4}{c|}{ ANOVA Statistics } \\
\hline Measure & ND. & Unique & df & F & p \\
\hline Read Message & 94.0 & 96.1 & 1,18 & 0.20 & .6584 \\
\hline Spoke Message & 73.4 & 75.8 & 1,18 & 0.26 & .6163 \\
\hline
\end{tabular}

\subsubsection{Pilot Flying.}

During the Data Link text-only flights, the PNF typically handled Data Link traffic and often read out loud each incoming message. However, the PF usually glanced at the D ata Link display and sometimes also read the message and repeated it out loud. It was hoped that with the provision of digitized speech of Data Link messages, the need for this kind of crew cross-checking would be reduced.

Videotapes for all flights were analyzed and comparisons of crew activities were made for the three experimental factors. For the cockpits with different alerting systems, there were no significant effects of alerting system on number of PF glances, glance duration, how often the PF read the message, or how often the PF read the message out loud (as shown in table 17).

\section{TABLE 17. PERCENT OF TOTAL DATA LINK MESSAGES}

\begin{tabular}{|l|c|c|c|c|c|}
\cline { 2 - 6 } \multicolumn{1}{c|}{} & Crew Alert & \multicolumn{4}{c|}{ ANOVA Statistics } \\
\hline Measure & ND. & Unique & df & F & p \\
\hline Glanced at CDU & 84.1 & 84.8 & 1,18 & 0.01 & .9182 \\
\hline Glance $>1 \mathrm{~s}$ & 60.0 & 75.6 & 1,18 & 2.42 & .1376 \\
\hline Read Message & 48.2 & 58.4 & 1,18 & 0.58 & .4572 \\
\hline Spoke Message & 26.7 & 37.6 & 1,18 & 1.32 & .2657 \\
\hline
\end{tabular}




\subsubsection{CDU Location.}

\subsubsection{Pilot Not Flying.}

Table 18 shows that no significant difference existed between CDU location simulators for the number of times the PNF read the incoming D ata Link message or spoke it out loud.

\section{TABLE 18. PERCENT OF TOTAL DATA LINK MESSAGES}

\begin{tabular}{|l|c|c|c|c|c|}
\cline { 2 - 6 } \multicolumn{1}{c|}{} & CDU Location & \multicolumn{4}{c|}{ ANOVA Statistics } \\
\hline Measure & Aft. & Fwd. & df & F & p \\
\hline Read Message & 95.5 & 93.8 & 1,18 & 0.11 & .7474 \\
\hline Spoke Message & 78.7 & 75.4 & 1,18 & 0.28 & .6060 \\
\hline
\end{tabular}

\subsubsection{Pilot Flying.}

There was a statistically significant difference in the number of times the PF looked at the Data Link CDU as a function of CDU location. However, for those mistakes when the PF did look at the CDU there were no differences in the length of the glance, how often the PF appeared to read the message, or how often the PF read the message out loud. The means and ANOVA statistics are shown in table 19. The percent of total Data Link messages that PF glanced at CDU, glanced for more than 1 second, read the message, or read it out loud for display location cockpits. (The effect of communication type has been removed from these analyses. ${ }^{1}$ )

\section{TABLE 19. PERCENT OF TOTAL DATA LINK MESSAGES}

\begin{tabular}{|l|c|c|c|c|c|}
\cline { 2 - 6 } \multicolumn{1}{c|}{} & \multicolumn{2}{l|}{ Location } & \multicolumn{4}{c|}{ ANOVA Statistics } \\
\hline Measure & Aft. & Fwd. & df & F & p \\
\hline Glanced at CDU & 33.5 & 76.1 & 1,18 & 26.55 & .0001 \\
\hline Glance > 1 s & 69.6 & 62.3 & 1,18 & 1.52 & .2338 \\
\hline Read Message & 24.6 & 43.1 & 1,18 & 2.69 & .1185 \\
\hline Spoke Message & 27.9 & 40.0 & 1,18 & 1.95 & .1800 \\
\hline
\end{tabular}

\subsubsection{Communication Type.}

\subsubsection{Pilot Not Flying.}

There was a difference across communication conditions for the percentage of D ata Link messages that the PNF read out loud from the screen. ${ }^{2}$ The average for text-only was 94.4 percent and for speech was 57.3 percent, $F(1,36)=82.9$, $\mathrm{p}=.0001$. 5.4.3.2 Pilot Flying.

It was found that there was a significant difference between the two Data Link communication conditions in percent of the total Data Link transmissions the PF looked at the Data Link display. It was also shown that PF glances were more than 1 second for Data Link text-only presentations and that the PF appeared to read the messages on the CDU more frequently in text-only conditions. There was no significant difference in the proportion of transmissions that the PF read the incoming message out loud. These results are shown in table 20.

\section{TABLE 20. PF ACTIVITIES FOR ALL SIMULATORS (IN PERCENT)}

\footnotetext{
1 These results were averaged over both Data Link communication conditions. The presence of digitized speech reduced PF glances for both CDU locations by about the same amount.

2 There was no comparison of text-only versus voice for reading the display in this case since it was assumed that the $\mathrm{PNF}$ read the display in the text-only condition and this was not counted.
} 


\begin{tabular}{|l|c|c|c|c|c|}
\cline { 2 - 6 } \multicolumn{1}{c|}{} & Data Link Mode & \multicolumn{3}{c|}{ ANOVA Statistics } \\
\hline Measure & DL Text & DL Speech & df & F & p \\
\hline Glanced at CDU & 76.4 & 62.9 & 1,36 & 20.83 & .0001 \\
\hline Glance > 1 s & 72.2 & 61.5 & 1,36 & 7.37 & .0101 \\
\hline Read Message & 61.9 & 43.6 & 1,36 & 17.24 & .0002 \\
\hline Spoke Message & 34.1 & 31.6 & 1,36 & 0.34 & .5658 \\
\hline
\end{tabular}

\subsubsection{Both Pilots.}

O bservations were made from the cockpit videotapes of whether the PF or PNF read the Data Link message verbatim, or in some abbreviated form. This was motivated by interest in whether a reduction in crew coordination occurred when Data Link digitized speech was provided. The average number of times D ata Link messages were read verbatim was 47.1 percent in text-only mode and 9.3 percent in speech mode, $F(1,36)=92.14, p=.0001$. Provision of digitized speech resulted in a significant reduction in reading the full message out loud.

\subsubsection{Navigational Input.}

It was important for the analysis of pilot-controller Data Link interaction that the relationship between aircrew navigational inputs and WILCO of Data Link messages be established. It was found that in an average of 87.5 percent of Data Link transactions, flight crews began to change the flight simulator's track before making the WILCO response. There was no difference between simulators, $F(3,36)=2.01, p=.1303$ (and therefore no effect of alerting or CDU location) or for Data Link communication type, $F(1,36)=1.71, p=.2000$.

\subsection{FUEL BURN.}

A mount of fuel burned during each flight was recorded and comparisons were made between each pair of simulators. There was no significant difference between simulators for CDU location but a significant difference emerged for the crew alert factor. The means and ANOVA statistics were shown in table 21. 
TABLE 21. FUEL BURN FOR EACH SIMULATOR (IN POUNDS)

\begin{tabular}{|l|c|c|c|c|c|}
\cline { 2 - 6 } \multicolumn{1}{c|}{} & Means & \multicolumn{3}{c|}{ ANOVA Statistics } \\
\hline Test & Sim. A & Sim. B & df & F & p \\
\hline CDU Location & 1547.13 & 1661.78 & 1,18 & 2.00 & .1740 \\
\hline Crew Alerting & 1265.77 & 2213.77 & 1,18 & 74.35 & .0001 \\
\hline
\end{tabular}

Fuel burn comparisons were also made for type of communication (radio, D ata Link text, and D ata Link with digitized speech). No significant differences were found. The average fuel consumptions for radio, Data Link text, and D ata Link speech were $1640.1,1715.8$, and 1660.5 pounds, respectively and there were no significant differences as a function of communication, $\mathrm{F}(2,72)=1.45, \mathrm{p}=.2414$.

\subsection{QUESTIONNAIRE DATA.}

At the end of each run and at the end of the day, pilots answered questions that dealt with the human factors and cockpit integration issues associated with Data Link. The items dealt with the quality of the D ata Link alert, reach, vision, and readability of the display and overall useability.

\subsubsection{Crew Alert.}

The aircrews participating in the simulators with differing crew alerts received identical questions regarding Data Link ergonomics. The results of these measures are presented in table 22. The CDU received above average ratings in all categories. There were no significant differences between the two sites with respect to CDU ergonomics.

\section{TABLE 22. CREW ALERT CDU ERGONOMICS(0 TO 5 SCALE)}

\begin{tabular}{|c|c|c|c|c|c|}
\hline & Crew Alert & \multicolumn{4}{|c|}{ Fisher's t Statistics } \\
\hline Measure & ND. & Unique & $\mathrm{df}$ & $\mathrm{t}$ & $\mathrm{p}$ \\
\hline Alert & 4.5 & 3.7 & 9 & 1.5 & .1679 \\
\hline Vision & 4.5 & 3.8 & 9 & 1.7 & .1207 \\
\hline Reach & 3.8 & 3.4 & 9 & 0.6 & .5506 \\
\hline Readability & 4.2 & 4.0 & 9 & 0.6 & .5728 \\
\hline Useability & 4.2 & 3.9 & 9 & 1.0 & .3434 \\
\hline
\end{tabular}

Some pilots also offered written comments on the effectiveness of the Data Link alert. The most common criticism was that of the tone and its lack of distinction from the company SELCAL tone. It was recommended that the Data Link tone be different from the SELCAL, and possibly different from any other sound in the cockpit. There were conflicting opinions about the glare shield lights that accompanied the tone. Several pilots thought they were effective and appropriately located, and others found them distracting and improperly located as they could have been mistaken for caution/ advisory lights. At the site without glare shield lights one pilot commented that the tone and light located on the CDU was a very effective alerting combination. 


\subsubsection{CDU Location.}

The results of the location questionnaire are presented in table 23. The CDU received above average (greater than 3) ratings in all areas except for vision for the aft-CDU installation. The crews with the aft-mounted display found it significantly less visible than those using the forward-mounted arrangement. The aircrews were most pleased with the readability of the characters on the display. Reach and the Data Link alert received the lowest ratings.

\section{TABLE 23. CDU LOCATION ERGONOMICS (0 TO 5 SCALE)}

\begin{tabular}{|l|c|c|c|c|c|}
\cline { 2 - 6 } \multicolumn{1}{c|}{} & \multicolumn{3}{c|}{ CDU Location } & \multicolumn{3}{c|}{ ANOVA Statistics } \\
\hline Measure & Aft. & Fwd. & df & t & 0.7 \\
\hline Alert & 3.9 & 3.6 & 9 & 3.5 & .2602 \\
\hline Vision & 2.6 & 4.2 & 9 & 0.2 & .0063 \\
\hline Reach & 3.3 & 3.4 & 9 & 0.7 & .8683 \\
\hline Readability & 4.1 & 4.4 & 9 & 0.7 & .4961 \\
\hline Useability & 3.5 & 3.7 & 9 & 0.4 & .7353 \\
\hline
\end{tabular}

Pilots were asked to provide written comments on the location of the Data Link CDU. Responses from those at the simulator site with the unit positioned in the forward location noted good visibility of the display. O ne pilot noted, however, that the Data Link operator's arm interfered with the pilot flying when he advanced the throttles. When the display unit was located in the aft position, at the O klahoma City simulator site, several pilots commented that it was in the way of the autopilot controls and could not always be easily viewed.

\subsubsection{Communication Type.}

Immediately after each run, pilots were asked to rate ease of communication, confidence, ease of flight planning, and perceived safety of each communication type (on a 0 to 5 scale). The average ratings for each question for each communication type are shown in table 24 .

TABLE 24. AVERAGE PILOT RATINGS OF COMMUNICATION OPTIONS

\begin{tabular}{|l|c|c|c|c|c|c|}
\cline { 2 - 7 } \multicolumn{1}{c|}{} & \multicolumn{3}{c|}{ Communication Type } & \multicolumn{3}{c|}{ ANOVA Statistics } \\
\hline Test & Radio & DL Speech & DL Text & $\mathrm{df}$ & $\mathrm{F}$ & \multicolumn{1}{c|}{$\mathrm{p}$} \\
\hline Ease of Use & 3.8 & 4.0 & 3.9 & 2,72 & 0.79 & .4585 \\
\hline Confidence & 4.1 & 3.7 & 3.5 & 2,72 & 4.36 & .0164 \\
\hline Planning & 3.9 & 3.5 & 3.5 & 2,72 & 2.91 & .0611 \\
\hline Safety & 4.1 & 3.6 & 3.5 & 2,72 & 6.34 & .0029 \\
\hline
\end{tabular}

There were significant differences for pilot confidence and perceived safety. In each case, radio communication was seen as the most highly rated option; differences between Data Link with or without speech were minimal.

At the end of each day, aircrews were asked to rate the effectiveness of the message delivery mode; text-only versus text plus digitized speech. This item was analyzed for all simulators. The average ratings were 3.5 and 4.1 (on a 0 to 5 scale) for text and speech, respectively. However, there was a significant interaction between the communication type and simulator site factors, $\mathrm{F}(3,36)=2.86, \mathrm{p}=.0522 .{ }^{1}$ This means that the overall difference between the two communication types must be interpreted with respect to each flight simulator. Figure 7 shows a graph of the results.

Figure 7 indicates that, while digitized speech was generally preferred over a text-only presentation, it appears that the difference only existed at two simulator sites, NASA and O klahoma City. The latter simulator had the aft-mounted display.

\footnotetext{
1 Given the pre-established cutoff for statistical significant of p<.05, this finding is only marginally significant. Nevertheless, this result has implications that should be considered.
} 
The pilots addressed the effectiveness of the message delivery mode (i.e., text-only versus text with speech) in written comments. Most of the pilots who offered information found the digitized speech accompanied by the display of text to be more effective than the text alone. However, a problem occurred when the digitized voice spoke at the same time as an ATC radio transmission that resulted in difficulty in understanding either of the messages.

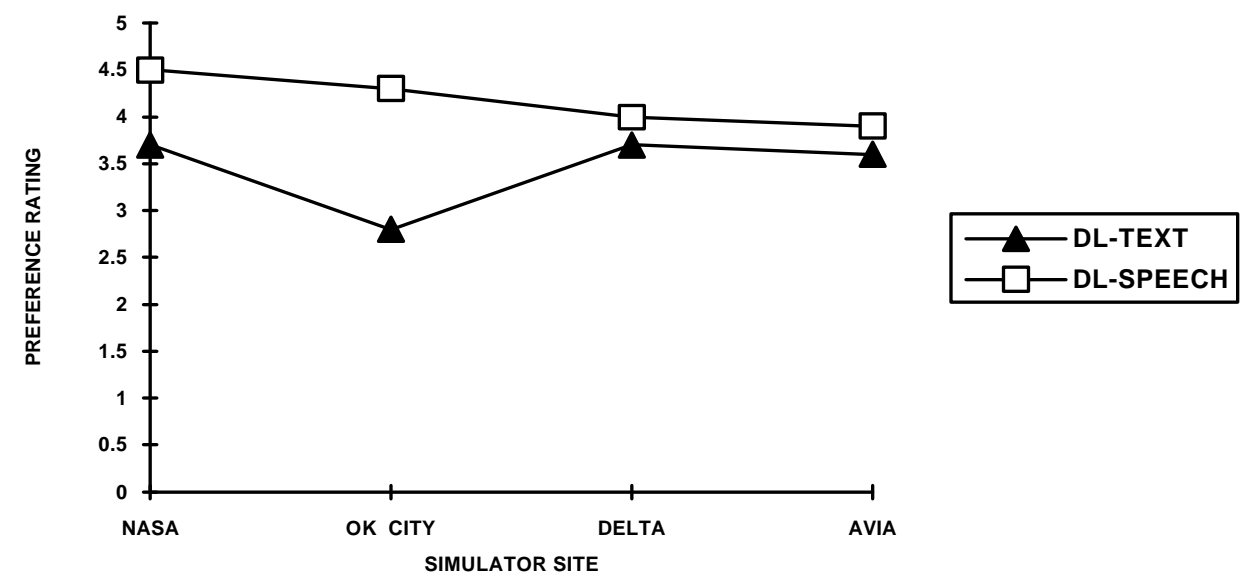

FIGURE 7. INTERACTION PLOT FOR PILOT OPINION

\subsubsection{Other Pilot Comments.}

Pilots also commented on the ease of use of accessing and responding to Data Link messages. O ne pilot thought the commands were clear with regard to what to do and what aircraft was being assigned to do it. Several pilots suggested having the WILCO button flash until pushed. O thers suggested having either the DIR button or the WILCO button on the yoke, instead of having to reach over to the center console. O ne pilot proposed having the DIR button light up along with the Data Link message.

A nother issue addressed was the readability of the Data Link messages on the display. Several pilots commented that each separate item of data needed to be on its own separate line. Two line "cleared for the approach" messages were confusing to interpret.

Additional criticisms the pilots had concerning the Data Link man-machine interface were as follows:

a. Too much head down time in terminal area would be excellent for en route, for initial clearance when entering terminal airspace, or for oceanic crossings.

b. There has to be two-way radio communication available at all times for questions, comments, etc.

c. Much quieter cockpit and less chance of missing calls from ATC; able to concentrate more on the approach.

d. ATC radio communications should override the digitized speech.

e. Should have a method for determining that Data Link is operating, like the green light on the transponder.

f. Data Link display may be a problem to read with sunlight reflecting on the display.

g. Display did not advise which way to turn to new headings, could cause for a turn in the wrong direction.

h. Unsure that aircrew transmissions were received by ATC. 
The review of the preceding results will focus on the three research questions identified in section 1.4. These are crew alerting, display location, and method of Data Link message presentation.

\subsection{CREW ALERTING.}

The original research question was: What kind of alerting scheme is required to distinguish alerts for Data Link messages from other cockpit alerts? The possibilities for testing various alerting options were limited in this study. However, a nondistinctive alert (SELCAL sound only) in the AVIA flight simulator was contrasted with a nondistinctive alert combined with a unique annunciator lamp in the Delta simulator.

The primary measure of the effect of alerting type was pilot response time for the alert epoch (crew alert to pressing the DIR key). There was no significant difference in response time between simulators with nondistinctive versus unique alerts. Pilot comments suggested the small D SPLY light on the D ata Link CDU may have acted as a unique visual alert. It may be that the presence of this indicator in the nondistinctive alert simulator helped reduce response times. However, this is unlikely given that it was out of the forward field of view of the crews.

There was a significant difference in the WILCO epoch between the two simulators with the nondistinctive alert being faster. It would not be expected that type of crew alerting would have any effect on WILCO epoch times. O nce the Data Link message had been accessed, the type of alert should not make any difference. Upon discussion of these data with the respective cockpit observers, it was discovered that it had been suggested to the AVIA flight crews that they WILCO Data Link messages before making navigational changes to the aircraft. This was apparent in the videotape observations in that the AVIA crews made changes to the aircraft before WILCO for 80.4 percent of all Data Link messages while Delta crews did this 94.7 percent of the time. It is suspected that the effort to WILCO immediately by at least some of the crews at the AVIA site created the observed difference in WILCO epoch times.

The difference is of interest because it suggests that WILCO epoch times could be significantly shortened if a cockpit procedure was adopted to WILCO before making navigational inputs to the aircraft. This may be desirable from the ATC perspective in that controllers may prefer seeing a WILCO response before they observe an aircraft path change on radar.

There were no differences in heading or altitude path change times as a function of type of crew alerting. It would not be expected that the time required for the aircraft to respond to a D ata Link message would be affected by method of crew alerting.

There were no subjective effort differences (workload, time busy, amount of thinking, and general stress) for the PF or $\mathrm{PNF}$ as a result of different types of crew alerting. There were also no significant differences in the number of times the PNF read the Data Link message or read it out loud as a function of alerting type. The number of times the PF glanced at the CDU, the length of glance, or number of times the message was read or spoken out loud were also not affected.

There was no difference in fuel efficiency between the two simulators. This is not surprising in that crew alerting time would not be expected to effect fuel economy in any meaningful way.

Pilots were also asked to give their opinions regarding the two kinds of crew alerting. No significant differences in the CDU ergonomics rating scales were found between the two simulator sites. There were some comments that the alerting sound used should be distinctive and not a general purpose cockpit alert. Some pilots thought the glare shield lights were inappropriate and one pilot liked the idea of the indicator lamp on the CDU. It should be noted that crews did not have the opportunity directly to compare the alerting systems.

To summarize, the response time data do not indicate an advantage for either crew alerting option. Although it was hypothesized that the unique alert would result in faster response times, this was not supported. In addition, no suggestion of an advantage for either alert condition was found in the subjective effort or opinion scales. However, 
there were a number of pilot comments relevant to this issue, with emphasis on the provision of a unique Data Link sound. 


\subsection{DISPLAY LOCATION.}

The second research question was: What is the acceptability of an aft-center pedestal-mounted CDU given head-up requirements of terminal operations? Both the first and second response time epochs were relevant to this question. There was a good likelihood that the aft-mounted Data Link CDU would create longer alert and response epochs.

There was a significant alert epoch time difference between the cockpits with aft-mounted and forward-mounted displays. It required 0.4 seconds longer (on the average) for the flight crews to press DIR in response to a Data Link alert in the aft-mounted display position. Although there was a 1.4 seconds difference between the simulators in average time from DIR to WILCO, this was not statistically significant. It appears that, although it took slightly longer to reach to the rear-mounted display, once the PNF was attending to the Data Link message, it required no longer to respond to it. In fact, there was a statistically nonsignificant trend toward WILCO responses being shorter with the aft CDU. In-flight observers noted that the crews with aft displays, once they had turned to access an incoming message, tended to complete each Data Link transaction immediately and (while turned away from the main instruments) were not as distracted by other cockpit demands as crews with forward-mounted CDUs.

There were no differences in heading or altitude path change response times related to display location. Given the marginal overall differences in alert epoch times for the two locations, it is not surprising that aircraft response time was unaffected.

On the subjective effort scale, PNFs (who were responsible for Data Link operation) rated the aft-mounted display as significantly higher in workload, and the other effort factors approached statistical significance, favoring the forwardmounted display. These results corresponded with the slightly longer alert epoch times for the aft-mounted display. PFs did not indicated any difference in any effort measure between the two display locations.

Videotape analysis yielded a number of kinds of information about display placement. With regard to the PNF, there were no effects of CDU location on the number of times this crewmember read or spoke a Data Link message. Thus, it can be assumed that the PNF's duty to read out each Data Link message was carried out in a similar way for each CDU configuration.

It was found that the PF did not glance at the Data Link CDU as often when it was mounted in the aft location (about 76 percent for forward-mounted and 34 percent for aft-mounted). This result was statistically significant with the effect of communication type (text-only and text with speech) removed. Given that it would probably be the PF's role to validate the content of the Data Link message, the aft-mounted display would make this more difficult.

The length of the average glance, number of times the PF read the message, or read it out loud were not affected by display location. It appears that those PFs who used the aft-mounted display almost always read the Data Link message out loud if they glanced at the CDU.

There was a significant difference in fuel burn between the two simulators with the B-737 being more efficient. This was probably not a function of display location, but because the B-727 consumed more fuel being modeled on an older, less efficient aircraft.

The questionnaire data with respect to CDU ergonomics covered the following factors: alert, vision, reach, readability, and usability. The only significant difference for the display location factor was in vision; the aft-mounted display was rated as less visible that the forward-mounted CDU. Written comments indicated a small number of notes regarding problems with forward and aft CDU placement. However, there was an absence of real criticism of the aft-mounted display. Flight crews did not have a chance to make a direct comparison between CDU location types.

In summary, there was a small advantage for the forward-mounted D ata Link CDU in the amount of time required to respond to a D ata Link message. However, there was no significant difference in time required to respond to messages or in aircraft path change times. The aft-mounted display was rated as higher in workload by PNFs but did not significantly affect other effort factors for the PNF or any of the effort measures for the PF. The aft CDU was rated lower in visibility by crews but there were few negative comments about its location. 
In all flight simulators, Data Link messages were presented in one of three modes: radio, Data Link text-only messages on the CDU, or Data Link messages on the CDU accompanied by digitized speech. There were a number of kinds of data that were relevant to a comparison of these three communication modes.

\subsubsection{Radio, Data Link Text, and Data Link with Digitized Speech.}

The availability of Data Link significantly reduced controller radio communication with pseudopilots and simulator pilots. The frequency of push-to-talks and the total duration of radio communication during Data Link runs were 26 percent of the equivalent measures found under radio-only conditions.

While no statistically significant differences were found for Data Link communication type for the alert or path change epochs in any simulator, time required to WILCO was longer for digitized speech. Videotape review of crew activities indicated that pilots were able to read messages from the CDU faster than the time required for the digitized speech to play but were prevented (by the software) from WILCO ing until the speech was completed. If the messages had been recorded at a faster rate, this time disadvantage for the speech mode might have disappeared. However, it is likely that reading text from the screen will always be faster than waiting to hear a spoken version.

Four types of SA data were collected during the study. With regard to flight crew responses to problem weather reports, there were no statistically significant differences between communication types, but a trend was evident. There was slightly more crew discussion about the weather situation in Data Link runs, especially for text-only. If there was discussion in a Data Link condition, it appeared to be less frequent for Data Link with speech and more frequent for Data Link text-only as compared to radio.

The map and probe question SA data demonstrated more graphic differences between Data Link and radio-only. Raw recall of aircraft information was less than one item per flight (on average) during Data Link runs. However, when radio was used exclusively, pilots recalled an average of three items per flight. Accuracy rates were 0.7 items per flight averaged across Data Link conditions and 2.3 items per flight with radio.

The probe question data were similar in that the raw answer rate for radio-only was nearly twice as great as for Data Link. They were accurate for 0.3 items per flight for Data Link conditions and 1.0 items per flight for radio conditions.

Q uestionnaire data gathered immediately after each run showed no significant differences across communication conditions for ease of use or planning capability but indicated that Data Link was seen by pilots as promoting less confidence and safety. Ratings on an end-of-day SA questionnaire revealed that pilots thought Data Link would result in a reduction in knowledge of weather and separation from other aircraft and would reduce aircrew ability to anticipate ATC instructions, clearances, next sector, and landing sequence. (Respondents were not asked to distinguish between text and speech versions of Data Link.) In their written comments, most pilots were concerned that Data Link would reduce their ability to detect A TC errors.

There were no significant differences in PNF or PF subjective effort ratings between radio and the two Data Link display conditions for all sites. This indicates that the method of communicating ATC messages did not seem to affect crew workload in any measurable way.

Crew communication activities were influenced by communication mode. With the provision of digitized speech, the PF glanced at the CDU significantly less often and glance duration was shorter. The PF read Data Link messages more often in text-only conditions. The PNF's duty to glance at the CDU to read incoming Data Link transmissions did not change with the provision of digitized speech. However, when speech was provided, the PNF read D ata Link messages out loud less frequently. It was also found that the PF and PNF did not read out the Data Link message verbatim as often when speech was available. Thus, there were definite shifts in crew activities in the direction of less work confirming D ata Link messages. Changes in these activities were however not reflected in the subjective effort measures. This suggests that global estimates of effort may not be sensitive to subtle changes in aircrew work patterns. 
Given the lack of any large differences in response times as a function of type of communication, it is not surprising that the efficiency (fuel burn) of the aircraft was not affected. For flights longer than those completed during this terminal airspace study where communication delays are common, faster communication might have a measurable effect on fuel consumption.

When asked about their preferences for digitized speech over a text-only presentation, pilots showed a significant difference of opinion. The ratings for D ata Link with speech averaged 4.1 (on a 0 to 5 scale) and 3.5 for text-only. However, further analysis indicated that the difference between speech and text-only Data Link was only present at two of the simulator sites. Crews who flew the simulator with the aft-mounted display had the poorest opinion of the text mode, rating it at 2.8 as opposed to 4.0 for speech (on a 0 to 5 scale). Display placement and a less visible position probably made the provision of speech more desirable. At the NA SA site, the rating for text was 3.7 and for speech 4.4. It is not known why crews at this site preferred the speech mode; the CDU configuration in this simulator was identical to that at the other two sites where no differences were found (except for the nondistinctive alerting arrangement at AVIA).

Pilot written comments were in favor of the digitized speech presentation of Data Link messages, although some improvements were recommended. They suggested that the speed of the speech should be increased (with speed controllable by the flight crew, if possible) and it should not interfere with radio traffic.

In summary, there were a number of findings that addressed the employment of Data Link in the cockpit. Pilot subjective effort was not reduced by the provision of Data Link, but neither was it increased. It appears that pilots did not perceive that Data Link created an unacceptable workload burden even when used in combination with radio. Fuel burn was not affected by communication type. On questionnaires, however, pilots associated Data Link with less confidence and reduced safety. They also expressed concern that their situation awareness would be degraded. This was confirmed by map and probe question SA results.

There were a number of indications that speech digitization could augment the display of cockpit Data Link information. Although speech did not appear to reduce overall workload, it did not create additional workload. There was a significant reduction in crew-coordination activities that amounted to a decrease in visual attention to the display on the part of the PF, fewer occasions when the PF felt the need to read the message, and a reduced requirement for the PNF to read D ata Link messages out loud. The provision of audible D ata Link messages appears to have reduced the need for crew coordination to cross check ATC instructions. Pilot opinion was also in favor of speech digitization.

\subsubsection{Message Type.}

When examining WILCO response times, it was found that there were significant differences between TI, MT, and TC message types. ${ }^{1}$ MT and TC response times were similar, but TI required a significantly longer time to WILCO than both of the others. This is understandable given that these messages typically had more segments and characters.

It became evident during the experiment that design of the TC WILCO response was poor. It required an average of 15.5 seconds to complete the third keypress and there were a number of occasions when flight crews forgot to complete the transaction.

\subsection{OTHER ISSUES}

In addition to the findings for the main questions of interest, a number of other types of interesting information emerged from this study.

1 Transfer of communication time was measured to the first acknowledgement key press. There were two more steps required to WILCO the message. 


\subsubsection{Total Data Link Response Time.}

The total amount of time required to access and respond to Data Link messages is important from the perspective of the air traffic controller. Controllers are used to rapid radio response from pilots and are reluctant to use D ata Link when there are long delays to receipt of WILCO s [9]. Previous research on crew response time in simulated en route and terminal environments indicated an average of 10 seconds (averaged across a number of studies) [10].

In this experiment, the shortest average alert epoch response time was 2.5 seconds (forward-mounted CDU, NASA cockpit) and the shortest WILCO time was 8.6 seconds (nondistinctive alert cockpit). Total turnaround time in the cockpit was therefore 11.1 seconds. This result is similar to that found in previous Data Link studies [10]. If the shortest path change epoch time (10.0 seconds for forward location, altitude changes) is then added, a total response time of 21.1 seconds would be expected. However, depending upon cockpit locations and configurations, average pilot response times were as long as 13.1 seconds (alert epoch time of 2.9 seconds for aft-mounted CDU and WILCO epoch time of 10.2 seconds for the forward-mounted CDU). ${ }^{1}$ Adding the longest path change time (15.3 seconds, aft location, altitude changes) could result in a total response time of 28.4 seconds.

\subsubsection{Navigational Input Before WILCO.}

Videotape analysis of flight crew activity immediately following the receipt of a Data Link communication revealed that for 87.5 percent of all messages, one of the pilots began making navigational changes to the aircraft (manually or through inputs to the autopilot) before WILCO ing. Although this result suggested that crew delay in WILCO ing a controller's Data Link instruction might result in the controller observing a change in aircraft track on the radar display before the WILCO response is received, the path change data suggested that this would not be the case. In a large majority of the $D$ ata Link transactions, a path change by the simulator was not detected by measures based on ARTS data until at least 11 seconds after the WILCO was recorded.

There were indications that even casual instructions to flight crews to WILCO prior to maneuvering resulted in faster response times. In the crew alerting simulator pair, the cockpit with the nondistinctive alert showed a significantly faster WILCO time (1.6 seconds) that was probably induced by a cockpit observer suggestion to WILCO before altering aircraft track.

1 All times are averaged across the three message types (MT, TI, and TOC. Message type had an effect on the WILCO epoch and would effect total response time. 


\subsubsection{CDU Ergonomics.}

Data Link CDUs in all cockpits received ratings of 3 or above with many ratings over 4 (on a 0 to 5 scale) on alert, vision, reach, readability, and usability. The only exception was for the aft-mounted display which was rated 2.7 for vision. Data Link was valued for its ability to provide text of ATC instructions so that pilots could check frequency changes, clearances, etc. These results indicate that the Data Link CDU was accepted well by flight crews.

A number of suggestions for improvement were made in written comments. Pilots mentioned on the ease of use of the Data Link interface and suggested making the WILCO button flash, having a DIR key on the yoke, allowing the radio to override Data Link speech, and improving system status displays. Difficulty with making TC responses was mentioned.

\section{CONCLUSIONS.}

The following conclusions are organized by issue, similar to the previous section.

\subsection{CREW ALERTING.}

As discussed in section 1.4 of this report, the setting for this study was not conducive to a definitive test of Data Link alerting possibilities. N evertheless, a nondistinctive alerting sound was evaluated against the same sound plus a unique annunciator lamp. There was no response time, subjective effort, crew activity, fuel efficiency, or preference rating differences supporting either option. The primary suggestion from flight crews appeared to be to change the selective calling (SELCAL) sound to a unique sound distinguishable from other cockpit aural indicators.

The data did not support the hypothesis that a unique alert would be more effective than a nondistinctive alert and also did not show it to be preferred by flight crews. This study has not established that the provision of a unique D ata Link alerting system in the terminal environment is needed. Contrary to predictions, there were differences in WILCO epoch times and fuel efficiency between the alert type cockpits. However, upon further analysis, these effects were determined to be due to other factors. It appears that, if simplicity in an alerting system is desired, a SELCAL sound alone may support acceptable crew performance.

However, one pilot's comment that the small control display unit (CDU) bezel light plus the SELCAL were an effective alerting combination suggests that the bezel light may have acted as a unique visual annunciator in the cockpit without the glare shield lamps. This could have enhanced the alert epoch response times in this simulator, although this light was in the pilots' peripheral visual fields. In addition, although attempts were made to create non-D ata Link events when the SELCAL sounded, these may not have been sufficient to distract the flight crews from assuming that SELCAL meant Data Link.

Analysis: The results of crew alert testing are inconclusive. For the terminal environment, there are indications that the use of a glare shield visual Data Link annunciator in B-727 or B-737 cockpits is not necessary and that the existing SELCAL sound may be sufficient. However, a further experiment focused exclusively on Data Link crew alerting is needed to address the unanswered questions.

\subsection{DISPLAY LOCATION.}

Although it required 0.4 seconds longer for the pilot not flying (PNF) to respond to a Data Link alert with the aftmounted display, this does not represent a meaningful time difference. This location was also associated with higher workload and lower visibility. Crew coordination may have been degraded in that the pilot flying (PF) did not look at the aft-mounted display as often. However, flight crews did not indicate a distinct preference (in their comments) for either location. There was a relative dislike for text-only presentation in the aft location, as compared to digitized speech. It appears that the use of speech with an aft-mounted display may offset some of its disadvantages.

The hypothesis that the aft-mounted display would require longer alert and WILCO epoch response times was partially supported as was the prediction that it would be associated with increased effort. Although it was anticipated that crew 
attention to Data Link would increase with an aft-mounted display, this was not confirmed by the PF and PNF activity analysis. In fact, PF glances decreased in frequency. Contrary to predictions, one other variable was affected: the aftmounted CDU was rated as lower in visibility.

A concern about the aft-mounted display is that the PNF must turn away from the main flight instruments and windscreen to operate and read the D ata Link display. With an average response time (alert to WILCO) of 11.1 seconds and an average of $10 \mathrm{D}$ ata Link messages per flight (as observed on cockpit video tapes), a total of about 2 minutes (1 minute, 51 seconds) of the PNF's time would be required. If the flight duration in the arrival and final sectors was about 20 minutes, use of the Data Link CDU would occupy about 10 percent of the PNF's time.

While this does not appear to represent a major shift in workload, further investigation is needed to determine if use of Data Link in the terminal area would prove to be overly distracting to the PNF. It may be that the requirement to look at the display (especially in the aft location) as opposed to interact verbally with air traffic control will be disruptive of important PNF tasks. Data Link involves use of the visual (as opposed to verbal) modality for ATC communication. There is an already heavy load of visually based tasks in the cockpit. The addition of 2 more minutes of similar work may create an overload on PNF visual and cognitive resources. However, it also may be possible that the PNF, who is not responsible for flying the aircraft, will adapt to Data Link functions with sufficient practice with no negative impact on other flight-related tasks.

Analysis: An aft-mounted Data Link CDU may be acceptable, if necessary, with certain qualifications. Crew crosschecking of Data Link information can be supported by procedures such as PNF announcement of screen contents. The provision of digitized speech would obviate the need for the PF to glance at the CDU and would ensure a reliable check on Data Link messages for both crew members. Future research should focus on the effects of Data Link (especially in aft-mounted locations) on PNF activities and provide the opportunity for pilots to make direct comparisons of both forward and aft installation options.

\subsection{COMMUNICATION TYPE.}

The availability of Data Link reduced the controller's reliance on radio by about 74 percent. This result underlines the value of $D$ ata Link in reducing radio traffic.

The finding that response epoch times were longer for Data Link speech was no doubt a function of the cadence of the controller's digitized speech. While this delay could be reduced by speeding up the speech rate, it is likely that pilots will usually be able to read faster than the message can be spoken. To avoid delaying a WILCO response, it might be wise to allow the WILCO input before the speech system has finished. This would allow the crew to read the message from the screen, WILCO, and still have the audible message for confirmation.

Data Link was generally well received by flight crews. Crew subjective effort was not affected by the presence of Data Link capabilities. However, there were concerns about situation awareness (SA). While the problem weather SA data suggested some increased discussion under Data Link conditions, there were clear indications of a loss of awareness for navigational information regarding surrounding aircraft in the map and probe question results. Q uestionnaire ratings also showed that pilots perceived Data Link to be associated with reduced confidence and safety and were concerned about the effects of the loss of the radio party line on their SA.

With regard to the use of speech digitization of Data Link messages, it was found that some PF and PNF coordination activities that involved glancing at and reading D ata Link messages were reduced when speech was provided. In two out of four of the simulators, pilots also preferred speech, especially when an aft-mounted display was in use.

The hypotheses stated in section 4.1 were generally supported. There were no alert or WILCO epoch response time differences that were attributable to D ata Link. SA data showed a decrease in information about other aircraft and concerns by pilots regarding this limitation. Results at two simulators showed a preference for $D$ ata Link with speech. However, one other dependent variable (crew attention to the CDU) was affected by Data Link. 
Analysis: Data Link was generally accepted by flight crews in this study and did not add significant workload. Much less use of the radio channel was evident with Data Link. The addition of speech digitization reduced the need for crew coordination activities. It appears that D ata Link text-only is not advisable for aft-mounted displays.

A notable loss in SA occurred under Data Link conditions. The effects of SA reduction on pilot performance are not yet scientifically established but pilots in this study gave clear indications of their concerns about confidence, safety, and SA reduction. Methods may have to be developed to offset the decrement in traffic SA when Data Link is in almost exclusive use as a communication medium.

\subsection{DATA LINK RESPONSE TIME.}

Best average cockpit turnaround time for D ata Link messages was 11.1 seconds.

A nalysis: Future Data Link studies can use this value as a realistic estimate of flight crew response times to D ata Link messages. It may be possible to reduce this time though implementation of specific cockpit procedures, such as to WILCO before making navigational changes.

\subsection{NAVIGATIONAL INPUT BEFORE WILCO.}

For most Data Link messages, flight crews were observed to make navigational inputs to their simulators before they WILCO ed. This was true irrespective of D ata Link condition. However, path changes were not detected at the ARTS site until after the WILCO had been recorded. This was no doubt due to the time lag between making a course or altitude change and recording this action on terminal radar. It probably means that controllers would not observe most path changes before noting a WILCO response even if they were initiated before the WILCO key was pressed. However, there is a concern that the WILCO might be delayed if flight crews become distracted by addressing the flight controls. This could result in longer than necessary WILCO times.

Analysis: The issue of flight crew-controller coordination should be discussed with regard to the desirability of this behavior. It may be necessary to institute a cockpit procedure to WILCO first so that controllers receive an early indication that the aircraft intends to comply to an ATC instruction.

\subsection{CDU ERGONOMICS.}

Data Link CDU s and software were rated as acceptable in most cases. However, there were problems with the transfer of communication (TC) response sequence and flight crews made a number of suggestions.

Analysis: Modify the TC sequence to improve throughput and error rate (noncompletion). Consider a flashing WILCO reminder, positioning the message access (DIR) key on the yoke, allowing radio to override Data Link speech, and improved system status displays.

\subsection{SUMMARY.}

This study has achieved a number of important goals. First, it has been established that the test bed developed for the experiment is capable of supporting an extensive cockpit Data Link study involving multiple simulators. A number of important data extraction tools have also been developed, including on-site PCs for D ata Link messages and crew response times, cockpit video systems, and software to extract response time and communication data from Data Link PC files, AMECOM records, and Automated Radar Terminal System (ART S) tapes.

While further study is required on crew alerting, information has been gathered that outlines the direction for this work. It has been tentatively established that aft-mounted Data Link CDUs are feasible, with certain qualifications. Pilot response time to Data Link messages in the terminal environment has been established (for the aircraft and conditions of this study) and is supported by a large number of data points. Finally, good progress has been made in establishing the viability of the chosen computer-human interface (CHI) design for cockpit Data Link and the feasibility and desirability of digitized voice for announcement of Data Link messages. 
[1] ARTS III Terminal Data Link Functional Specification, Federal Aviation Administration, Atlantic City, NJ, 1992.

[2] Human Factors Requirements for Data Link (D raft 7), ATA Information Transfer Subcommittee, Airline Transport Association, Washington, DC, 1992.

[3] Airplane Simulator Q ualification, (FAA A dvisory Circular, AC 120-40B), Federal Aviation Administration, Atlantic City, NJ, 1992.

[4] M. A. Pomykacz, "Report of Study on Airlines' Anticipated Near Future Cockpit Control and Display Capabilities and Plans for Data Link Communication," (DOT/FAA/CT-TN91/ 7), Federal Aviation Administration, Atlantic City, NJ, 1991.

[5] A. Rehmann, et al., "Report of Study on Airlines' Anticipated Near Future Cockpit Control and Display Capabilities and Plans for Data Link Communication-Part 2," Federal Aviation Administration, A tlantic City, NJ, 1992.

[6] A. H. Midkiff, and R. J. Hansman, "Identification of Important "Party Line" Information Elements and Implications for Situational A wareness in the Datalink Environment," Proceedings of the AEROTECH Conference and Exposition, Anaheim, CA, 1992.

[7] N. B. Sarter, and D. D. Woods, "Situation A wareness: A Critical but Ill-D efined Phenomenon," International Journal of Aviation Psychology, 1, pp. 45-57.

[8] K. R. Boff, and J. E. Lincoln, Engineering Data Compendium: Human Perception and Performance, AAMRL, Wright-Patterson AFB, Columbus, O H, 1988.

[9] N. J. Talotta, et al., "O perational Evaluation of Initial Data Link Terminal Air Traffic Control Services: Mini Study 2, Volume 1," (DOT/ FAA/CT-92/ 2), Federal A viation Administration, A tlantic City, NJ, 1992.

[10] K. Kerns, "Data Link Communication Between Controllers and Pilots: A Review and Synthesis of the Simulator Literature," (MP-90 W00027), MITRE Corporation, McLean, VA, 1990. 

APPENDIX A

VIDEO ANALYSIS PROCEDURE 
Videotapes were recorded of all experimental runs using a single camera mounted behind the pilots along the centerline of the cockpit. The purpose of this data collection was to analyze the crew responses prompted by uplink messages.

The following information was collected:

1. Glance at the CDU.

2. Glance of more than 1 second.

3. Evidence that the message had been read.

4. Speaking message contents out loud.

5. Speaking message contents out loud verbatim.

6. Simulator control inputs before or after WILCO.

Analysis of each Data Link uplink began with the cue of crew alert as observed on the videotape. In order to analyze the videotape data, a number of assumptions and rules had to be established to standardize the analysis. These are graphically depicted in figure A-1. A printed record of all Data Link uplink messages was available.

First, it was assumed that the PNF always glanced at the message on the Data Link CDU and so no data were collected for this event. This was logical in that the PNF had to push the message access (DIR) key upon hearing the Data Link alert and it was observed that this always involved a head turn toward the display. (In the case of the aft-mounted CDU, it also included a body movement.)

If the PF made a head movement toward the CDU immediately after the Data Link alert, it was counted as a CDU glance. (O bservations prior to the experiment indicated that a head turn was necessary to glance at the forward mounted CDUs.) O nce a PF glance had been established, it was categorized into less or more than 1 second.

If either the PNF or the PF then took some action (such as changing the autopilot controls) or verbalized in some way that was directly related to the content of the message, it was assumed that the message had been read. (If there was no direct evidence that the PNF or PF had read and somehow acted upon the specific contents of the Data Link message, the glance was not scored as a "read.")

The audio track on the videotape recorded cockpit vocalizations and conversations. It was possible to tell whether the PNF or PF read or spoke the uplink message out loud and whether it was read verbatim. 


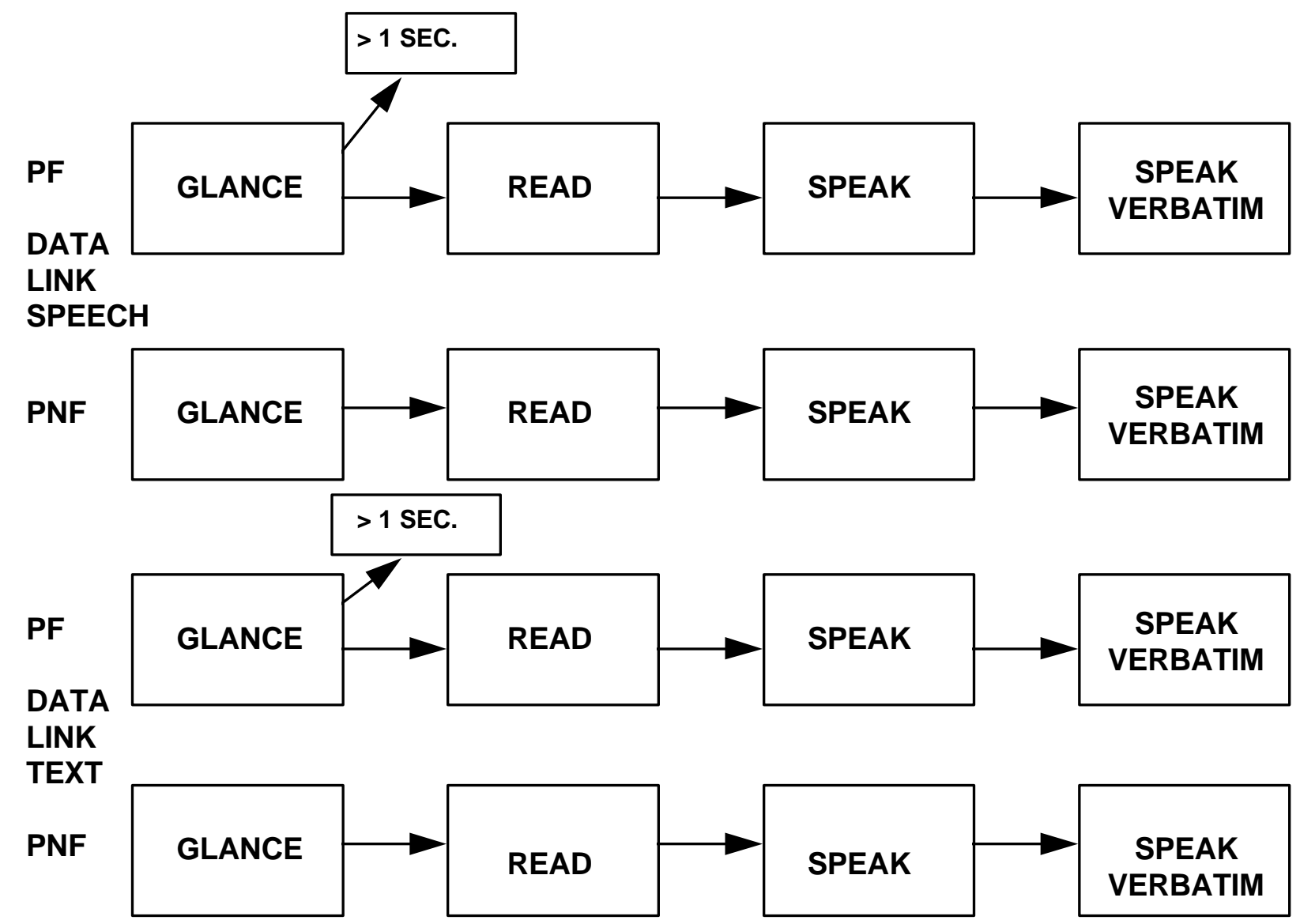

FIGURE A-1. VIDEO ANALY SIS FLOW CHART 